\title{
ARTICLE OPEN \\ 21st century California drought risk linked to model fidelity of the El Niño teleconnection
}

Robert J. Allen ${ }^{1}$ and Ray G. Anderson $\mathbb{1 0}^{2}$

\begin{abstract}
Greenhouse gas induced climate change is expected to lead to negative hydrological impacts for southwestern North America, including California (CA). This includes a decrease in the amount and frequency of precipitation, reductions in Sierra snow pack, and an increase in evapotranspiration, all of which imply a decline in surface water availability, and an increase in drought and stress on water resources. However, a recent study showed the importance of tropical Pacific sea surface temperature (SST) warming and an El Niño Southern Oscillation (ENSO)-like teleconnection in driving an increase in CA precipitation through the 21st century, particularly during winter (DJF). Here, we extend this prior work and show wetter (drier) CA conditions, based on several drought metrics, are associated with an El Niño (La Niña)-like SST pattern. Models that better simulate the observed ENSO-CA precipitation teleconnection also better simulate the ENSO-CA drought relationships, and yield negligible change in the risk of 21st century CA drought, primarily due to wetting during winter. Seasonally, however, CA drought risk is projected to increase during the nonwinter months, particularly in the models that poorly simulate the observed teleconnection. Thus, future projections of CA drought are dependent on model fidelity of the El Niño teleconnection. As opposed to focusing on adapting to less water, models that better simulate the teleconnection imply adaptation measures focused on smoothing seasonal differences for affected agricultural, terrestrial, and aquatic systems, as well as effectively capturing enhanced winter runoff.
\end{abstract}

npj Climate and Atmospheric Science (2018)1:21; doi:10.1038/s41612-018-0032-x

\section{INTRODUCTION}

In response to anthropogenic climate change, climate models from the Coupled Model Intercomparison Project (CMIP) version 3 and 5 indicate a likely transition to a more arid climate over many land areas, ${ }^{1}$ resulting in increased frequency and intensity of drought. ${ }^{2,3}$ Severe and widespread drought during this century are of particular concern for southwestern North America, including California (CA). ${ }^{4-8}$ This drying is a consequence of reduced precipitation in the subtropics, and a poleward expansion of the subtropical dry zones. ${ }^{9-13}$ Moreover, in addition to reduced precipitation, warmer temperatures will lead to an increase in evapotranspiration ${ }^{3}$ and a decrease in mountain snow mass. ${ }^{6}$ All of this translates into reduced surface water availability, soil moisture and runoff, $^{14}$ implying significant stress on water resources. Future drought risk in southwestern North America may even exceed that during the driest centuries of the Medieval Climate Anomaly. ${ }^{15,16}$

However, despite the large body of literature suggesting an increase in drought under greenhouse gas forcing, uncertainty still remains. Overall, there is medium confidence that warming will increase the duration and intensity of droughts in some regions, including the Mediterranean, Central America and Mexico, northeast Brazil, southern Africa and central North America. ${ }^{13,17}$ The only regions with a consistent increase in drought are those where precipitation decreases. ${ }^{18}$ Furthermore, many of the above studies quantify drought using the Palmer Drought Severity Index (PDSI), which is calculated from a simple water balance model, ${ }^{19}$ and may overestimate the increase in global drought ${ }^{20}$ due to an oversensitivity to warmer temperatures. ${ }^{21}$ Consistent with this uncertainty, a recent study suggests increased radiative forcing may lead to a decrease in the likelihood of CA agricultural drought. $^{22}$ This study, however, was based on a single model and did not focus on 21 st century climate change.

An important component of drought is precipitation, and relatively large uncertainty exists for future CA precipitation projections. ${ }^{23,24}$ Relative to CMIP3, however, CMIP5 CA precipitation projections tend to yield a more consistent increase. ${ }^{25-27}$ This is related to a coherent extratropical response, involving a southeastward extension of the the upper level winds in the east Pacific, ${ }^{25}$ an increase in storm track activity, ${ }^{28}$ and an increase in CA moisture convergence, ${ }^{29}$ all of which promote an increase in CA precipitation. Moreover, a robust dynamical response in the tropics also exists, ${ }^{27}$ including an increase in central/eastern tropical Pacific divergence and a poleward propagating Rossby wave, both of which are reminiscent of an El Niño-like teleconnection. Combined with warming of the tropical Pacific sea surface temperatures (SSTs), CMIP5 models that better simulate the observed El Niño-CA precipitation teleconnection yield larger, and more consistent increases in CA precipitation through the twenty-first century. ${ }^{27}$

Using a multitude of models from the CMIP $5^{30}$ archive, we build off of prior work ${ }^{27}$ and evaluate future CA drought risk using multiple metrics under business as usual warming. We primarily focus on annual drought to be able to compare our results to previous studies of future water availability in California and the Southwestern US from GCM simulations. ${ }^{4,31}$ More importantly, the question of potential changes in seasonal versus annual (and

${ }^{1}$ Department of Earth Sciences, University of California Riverside, Riverside, CA 92521, USA and ${ }^{2}$ Salinity Laboratory, USDA-Agricultural Research Service, George E. Brown Jr. Salinity Laboratory, 450 W. Big Springs Rd., Riverside, CA 92507-4617, USA

Correspondence: Robert J. Allen (rjallen@ucr.edu)

Received: 21 December 2017 Revised: 13 April 2018 Accepted: 27 April 2018

Published online: 03 September 2018 
inter-annual) drought greatly affects the feasible adaptation measures to climate change. If long-term water availability decreases, this will likely result in greater competition between agricultural, environmental, and urban users for California water and greater perennial stress on human and ecological systems. In this scenario, adaptation measures will need to focus on adapting to less water (including managing ecosystems as they transition to a drier state). If annual drought risk doesn't change, adaptation measures can focus more on smoothing seasonal differences for affected agricultural, terrestrial, and aquatic systems as well as effectively capturing enhanced winter runoff. These two scenarios have greatly different potential losses due to climate change as well as differing adaptation costs.

\section{RESULTS}

Tropical pacific sea surface temperatures and California hydrology Multiple studies ${ }^{2,32-39}$ have showed that SSTs are the dominant driver of changes in precipitation and drought in many world regions over the 20th century. For CA, the dominant source of SST variations that contribute to precipitation variations is El Niño/La Niña. Observations from $1948 / 49$ to $2014 / 15$ show the correlation between Niño 3.4 SSTs (5S-5N; 190-240E) and CA winter (DJF) precipitation is $\sim 0.3-0.4$, which is significant at the $99 \%$ confidence level. Although not all El Niño (La Niña) winters are wetter (drier) than normal since other factors also contribute to CA hydrological variations (e.g., meteorological noise and atmospheric rivers), and some evidence suggests the El Niño-CA precipitation relationship may not be stationary through time, ${ }^{40-42}$ this teleconnection represents a reasonably strong pathway by which CA precipitation variations occur. We also note that El Niño influence on California precipitation is strongest during late winter, and is stronger in the south than the north. ${ }^{43}$

As previously showed, models that better simulate the El NiñoCA precipitation teleconnection yield a very different projection of CA precipitation through the 21st century (Supplementary Discussion; Table 1). ${ }^{27}$ CMIP5 models with a 21 st century detrended CA DJF precipitation versus Niño 3.4 SST correlation of at least 0.30 (14 models and 29 realizations in total), referred to as "CMIP5 HIGH-r", yield larger and more consistent increases in CA precipitation (Supplementary 1 lists the models and correlations). The ensemble mean annual mean (ANN) CA precipitation trend is positive at $0.16 \mathrm{~mm}$ day $^{-1}$ century $^{-1}$, significant at the $99 \%$ confidence level (Methods). Furthermore, $73 \%$ of the modelrealizations yield an increase in CA ANN precipitation (Table 1). In contrast, models that yield a corresponding correlation less than 0.20 (12 models and 17 realizations), referred to as "CMIP5 LOW $-r$ ", yield more consistent decreases in 21st century CA precipitation. The ensemble mean ANN precipitation trend is $-0.15 \mathrm{~mm}$ day $^{-1}$ century $^{-1}$, significant at the $99 \%$ confidence level, and $76 \%$ of the model-realizations yield a decrease in CA ANN precipitation.

Most of the difference in CA ANN precipitation projections between CMIP5 HIGH-r and LOW-r occurs during DJF. CMIP5 $\mathrm{HIGH}-\mathrm{r}$ yields a significant increase of $0.84 \mathrm{~mm}$ day $^{-1}$ century $^{-1}$ (80\% realization agreement) whereas CMIP5 LOW-r yields a much weaker, and nonsignificant, increase of $0.09 \mathrm{~mm}^{\text {day }}{ }^{-1}$ century $^{-1}$, with low realization agreement of 59\% (Table 1) Non-winter seasons generally feature precipitation reductions in both model subsets, with drying trends during both March-April-May (MAM) and September-October-November (SON), particularly for CMIP5 LOW-r models (Table 1). Consistent with "robust spring drying" of the southwestern U.S. due to strengthening and expansion of the subtropical high pressure in the Pacific and Atlantic, ${ }^{44}$ the precipitation decrease is particularly robust during MAM.

We expand upon these results by first showing the importance of central/eastern tropical Pacific SSTs to other hydrological
Table 1. 21st century ensemble mean annual and seasonal CMIP5 hydrological trend statistics for California

\begin{tabular}{|c|c|c|c|}
\hline ANN & All & $\mathrm{HIGH}-\mathrm{r}$ & LOW-r \\
\hline Precipitation & $0.0656 \%$ & $0.1673 \%$ & $-0.1576 \%$ \\
\hline Precipitation-evapotranspiration & $\begin{array}{l}-0.02 \\
53 \%\end{array}$ & $0.0970 \%$ & $-0.2281 \%$ \\
\hline Snowfall (solid precipitation) & $\begin{array}{l}-0.12 \\
100 \%\end{array}$ & $\begin{array}{l}-0.10 \\
100 \%\end{array}$ & $\begin{array}{l}-0.15 \\
100 \%\end{array}$ \\
\hline Rainfall (liquid precipitation) & $0.1876 \%$ & $0.2683 \%$ & $-0.0147 \%$ \\
\hline Surface snow amount & $\begin{array}{l}-1.62 \\
100 \%\end{array}$ & $\begin{array}{l}-0.93 \\
100 \%\end{array}$ & $\begin{array}{l}-2.03 \\
100 \%\end{array}$ \\
\hline Total runoff & $0.0560 \%$ & $0.1373 \%$ & $-0.1878 \%$ \\
\hline Shallow soil moisture & $-0.980 \%$ & $-0.662 \%$ & $-1.6100 \%$ \\
\hline Deep soil moisture & $-4.661 \%$ & $-2.443 \%$ & $-9.792 \%$ \\
\hline DJF & All & $\mathrm{HIGH}-\mathrm{r}$ & LOW-r \\
\hline Precipitation & $0.5171 \%$ & $0.8480 \%$ & $\mathbf{0 . 0 9} 59 \%$ \\
\hline Precipitation-evapotranspiration & $0.3364 \%$ & $0.7079 \%$ & $-0.1456 \%$ \\
\hline Snowfall (solid precipitation) & $\begin{array}{l}-0.30 \\
100 \%\end{array}$ & $\begin{array}{l}-0.26 \\
100 \%\end{array}$ & $\begin{array}{l}-0.37 \\
100 \%\end{array}$ \\
\hline Rainfall (liquid precipitation) & $0.8284 \%$ & $1.1090 \%$ & $0.4776 \%$ \\
\hline Surface snow amount & $\begin{array}{l}-3.92 \\
100 \%\end{array}$ & $\begin{array}{l}-3.01 \\
100 \%\end{array}$ & $\begin{array}{l}-5.15 \\
100 \%\end{array}$ \\
\hline Total runoff & $0.3571 \%$ & $0.5790 \%$ & $-0.2767 \%$ \\
\hline Shallow soil moisture & $-0.8269 \%$ & $\begin{array}{l}-0.20 \\
43 \%\end{array}$ & $\begin{array}{l}-1.93 \\
100 \%\end{array}$ \\
\hline Deep soil moisture & $-2.955 \%$ & $1.362 \%$ & $-11.092 \%$ \\
\hline MAM & All & $\mathrm{HIGH}-\mathrm{r}$ & LOW-r \\
\hline Precipitation & $-0.2073 \%$ & $-0.1977 \%$ & $-0.3994 \%$ \\
\hline Precipitation-evapotranspiration & $-0.2990 \%$ & $-0.2783 \%$ & $\begin{array}{l}-0.45 \\
100 \%\end{array}$ \\
\hline Snowfall (solid precipitation) & $\begin{array}{l}-0.12 \\
100 \%\end{array}$ & $\begin{array}{l}-0.10 \\
100 \%\end{array}$ & $\begin{array}{l}-0.15 \\
100 \%\end{array}$ \\
\hline Rainfall (liquid precipitation) & $-0.0856 \%$ & $\begin{array}{l}-0.09 \\
63 \%\end{array}$ & $-0.2471 \%$ \\
\hline Surface snow amount & $\begin{array}{l}-2.44 \\
100 \%\end{array}$ & $\begin{array}{l}-0.60 \\
100 \%\end{array}$ & $\begin{array}{l}-2.87 \\
100 \%\end{array}$ \\
\hline Total runoff & $-0.1069 \%$ & $\begin{array}{l}-0.03 \\
57 \%\end{array}$ & $\begin{array}{l}-0.36 \\
100 \%\end{array}$ \\
\hline Shallow soil moisture & $-1.3694 \%$ & $-1.1895 \%$ & $\begin{array}{l}-2.01 \\
100 \%\end{array}$ \\
\hline Deep soil moisture & $-4.961 \%$ & $-2.562 \%$ & $-8.992 \%$ \\
\hline JJA & All & High-r & Low-r \\
\hline Precipitation & $0.0151 \%$ & $0.0763 \%$ & $-0.1182 \%$ \\
\hline Precipitation-evapotranspiration & $0.0457 \%$ & $0.0448 \%$ & $0.0169 \%$ \\
\hline Snowfall (solid precipitation) & $\begin{array}{l}-0.0003 \\
98 \%\end{array}$ & $\begin{array}{l}-0.0001 \\
95 \%\end{array}$ & $\begin{array}{l}-0.0007 \\
100 \%\end{array}$ \\
\hline Rainfall (liquid precipitation) & $0.0151 \%$ & $0.0763 \%$ & $-0.1182 \%$ \\
\hline Surface Snow Amount & $\begin{array}{l}-0.006 \\
94 \%\end{array}$ & $\begin{array}{l}-0.0002 \\
94 \%\end{array}$ & $\begin{array}{l}-0.0008 \\
78 \%\end{array}$ \\
\hline Total runoff & $-0.0274 \%$ & $-0.0167 \%$ & $-0.0478 \%$ \\
\hline Shallow soil moisture & $-0.7967 \%$ & $-0.5252 \%$ & $-1.3783 \%$ \\
\hline Deep soil moisture & $-6.071 \%$ & $-4.548 \%$ & $-9.792 \%$ \\
\hline SON & All & $\mathrm{HIGH}-\mathrm{r}$ & LOW-r \\
\hline Precipitation & $-0.0961 \%$ & $\begin{array}{l}-0.07 \\
50 \%\end{array}$ & $-0.2071 \%$ \\
\hline Precipitation-evapotranspiration & $-0.1368 \%$ & $-0.1048 \%$ & $-0.3081 \%$ \\
\hline Snowfall (solid precipitation) & $\begin{array}{l}-0.05 \\
100 \%\end{array}$ & $\begin{array}{l}-0.05 \\
100 \%\end{array}$ & $\begin{array}{l}-0.06 \\
100 \%\end{array}$ \\
\hline Rainfall (liquid precipitation) & & & $-0.1471 \%$ \\
\hline
\end{tabular}


Table 1 continued

\begin{tabular}{llll}
\hline & $-\mathbf{0 . 0 3}$ & $-\mathbf{0 . 0 2}$ & \\
& $53 \%$ & $47 \%$ & \\
Surface snow amount & -0.12 & -0.11 & -0.09 \\
& $100 \%$ & $100 \%$ & $100 \%$ \\
Total runoff & $-0.0249 \%$ & $-\mathbf{0 . 0 1}$ & $-0.0667 \%$ \\
& & $47 \%$ & \\
Shallow soil moisture & $-0.7069 \%$ & $-0.5652 \%$ & $-1.1983 \%$ \\
Deep soil moisture & $-4.767 \%$ & $-3.857 \%$ & $-9.083 \%$ \\
\hline
\end{tabular}

Seasons include December-January-February (DJF); March-April-May (MAM); June-July-August (JJA); and September-October-November (SON). Values are significant at the $95 \%$ confidence level, based on a standard $t$-test accounting for the influence of serial correlation, unless denoted with bold. Included is the percentage of realizations that yield a trend of the same sign as the ensemble mean

Trend units are $\mathrm{mm}$ day $^{-1}$ century $^{-1}$ for $\mathrm{P}, \mathrm{P}-\mathrm{E}$, rainfall, snowfall, and total runoff; and $\mathrm{mm}$ century ${ }^{-1}$ for soil moisture and surface snow amount

variables over CA. Figure 1 shows the 1979-2015 correlation between detrended annual mean soil moisture and SSTs in CMIP5 HIGH-r, CMIP5 LOW-r, and observations, including European Space Agency Climate Change Initiative (ESACCI) soil moisture observations ${ }^{45}$ from passive microwave sensors and Hadley Centre Sea Ice and Sea Surface Temperature data. ${ }^{46}$ Model correlations are based on 1950-1999, but similar results are obtained over different 20th century time periods (e.g., 1901-1999), as well as the 21 st century (not shown). Simulated soil moisture is based on shallow/intermediate depths $(0.2-1.0 \mathrm{~m})$, which corresponds to the depth over which the ESACCI passive soil moisture observations represent. A comprehensive evaluation of CMIP5 soil moisture simulations ${ }^{47}$ show that CMIP5 models are able to simulate the seasonal variability in soil moisture over the United States. However, models tend to overestimate near-surface $(0-10 \mathrm{~cm})$ and soil column soil moisture $(0-1 \mathrm{~m})$ in the western US.

ESACCI soil moisture observations show an EI Niño-like correlation pattern, implying anomalously high (low) CA soil moisture corresponds with anomalously warm (cold) central/ eastern tropical Pacific SSTs. This correlation patterns also exists in the models. CMIP5 LOW-r underestimates the observed correlation, whereas CMIP5 HIGH-r better reproduces it. Figure 1 also shows that similar, but somewhat stronger correlations are obtained between DJF SSTs and the subsequent June-July-August (JJA) CA soil moisture. Thus, the effects of El Niño/La Niña, which peak during Northern Hemisphere winter, are realized throughout the year, including during CA's dry season, when municipal, agricultural, and natural systems are most water stressed.

A similar El-Niño-like relationship exits for other observed drought indices over CA (Supplementary Discussion). This includes the Standardized Precipitation Index (SPI), the World Meteorological Organization's recommended index for monitoring abnormal dryness and wetness, ${ }^{48}$ as well as the observed Standardized Precipitation Evapotranspiration Index $(\mathrm{SPEI})^{49}$ and the selfcalibrated Palmer Drought Severity Index (scPDSI) ${ }^{50}$ (Supplementary Fig. 1). A similar relationship also exists between central/ eastern tropical Pacific SSTs and both CA precipitation minus evapotranspiration (P-E) and total runoff using the North American Land Data Assimilation System (NLDAS) version 2 models. ${ }^{51,52}$ Moreover, CMIP5 HIGH-r models better simulate these relationships, relative to CMIP5 LOW-r models (Supplementary Figs. 2-7).

To further isolate the relationship between SSTs and extreme CA dryness (drought) and wetness, Fig. 2 shows the normalized SST anomaly pattern associated with the five largest and five smallest CA annual mean soil moisture anomalies based on
ESACCI observations and CMIP5 models. Again, a distinct ENSOlike relationship exists in the observations, with CMIP5 HIGH-r models better reproducing this observed pattern, relative to CMIP5 LOW-r models. Similar results exist based on the SPI and SPEI (Supplementary Figs. 8 and 9). Furthermore, Fig. 2 shows that similar conclusions apply between DJF SSTs and the subsequent JJA CA soil moisture.

Thus, a significant relationship exists between anomalously warm (cool) central/eastern tropical Pacific SSTs and anomalously wet (dry) conditions in CA. These relationships exist on longer time scales (annual and longer) for all hydrological indicators, and also seasonally (DJF SSTs versus JJA hydrology) for soil moisture and runoff metrics, including the scPDSI. Moreover, CMIP5 HIGH-r models better simulate these relationships, relative to CMIP5 LOW-r.

\section{Surface water availability}

In the context of drought, not only is precipitation important, but so is evapotranspiration. Under business-as-usual (Representative Concentration Pathway 8.5, RCP8.5), CA is projected to warm significantly, ranging from 2.3 to $7.4 \mathrm{~K}_{\text {century }}{ }^{-1}$, with a multimodel mean of $5.0 \mathrm{~K}_{\text {century }^{-1}}$ and $100 \%$ model realization agreement (Supplementary Table 2). This warming results in enhanced evaporative demand of the atmosphere, which acts to reduce surface water availability (i.e., precipitation minus evapotranspiration, $\mathrm{P}-\mathrm{E})$. In terms of $\mathrm{P}-\mathrm{E}$, the CMIP5 RCP8.5 annual mean CA trend ranges from -0.77 to $0.53 \mathrm{~mm}$ day $^{-1}$ century $^{-1}$, with a non-significant multi-model mean of $-0.02 \mathrm{~mm} \mathrm{day}^{-1}$ century $^{-1}$. A decrease in CA ANN P-E occurs in 53\% of the model realizations (Table 1). Thus, although significant uncertainty exists, the CMIP5 multi-model mean suggests enhanced evapotranspiration exceeds the increase in precipitation, resulting in a reduction in surface water availability.

Extending this analysis to surface water availability, CMIP5 $\mathrm{HIGH}-\mathrm{r}$ yields an ensemble mean ANN P-E increase of $0.09 \mathrm{~mm}$ day $^{-1}$ century $^{-1}$, significant at the $99 \%$ confidence level, with $70 \%$ of the model realizations yielding an increase (Table 1; Fig. 3). As with precipitation, CA P-E increases more from south to north, with P-E decreasing by $-0.06 \mathrm{~mm}$ day $^{-1}$ century $^{-1}$ in southern $\left(32.0-34.9^{\circ} \mathrm{N} ; 239.4-245.6^{\circ} \mathrm{E}\right)$ California, but increasing to 0.11 and $0.22 \mathrm{~mm}$ day $^{-1}$ century $^{-1}$ in central $\left(34.9-38.6^{\circ} \mathrm{N} ; 236.9-243.1^{\circ} \mathrm{E}\right)$ and northern $\left(38.8-42.4^{\circ} \mathrm{N} ; 235.6-240.6^{\circ} \mathrm{E}\right)$ California, respectively, all significant at the $99 \%$ confidence level. In contrast, CMIP5 LOW-r shows the opposite response-an ensemble mean ANN P-E decrease of $-0.22 \mathrm{~mm} \mathrm{day}^{-1}$ century $^{-1}$, significant at the $99 \%$ confidence level, with $81 \%$ model realization agreement. All three $C A$ regions experience a significant $\mathrm{P}-\mathrm{E}$ decrease (Supplementary Table 2). Thus, unlike the entire CMIP5 database-and in particular CMIP5 LOW-r-the increase in CA precipitation in CMIP5 HIGH-r exceeds the increase in CA evapotranspiration.

As with precipitation, however, the increase in surface water availability in CMIP5 HIGH-r models primarily occurs during DJF (Table 1; Fig. 3). CMIP5 HIGH-r yields a significant increase in DJF CA P-E of $0.70 \mathrm{~mm}$ day $^{-1}$ century $^{-1}$, with $79 \%$ realization agreement. In contrast, CMIP5 LOW- $r$ yields a nonsignificant decrease of $-0.14 \mathrm{~mm}$ day $^{-1}$ century $^{-1}$ (56\% realization agreement). Non-winter seasons, particularly MAM, generally feature significant $\mathrm{P}-\mathrm{E}$ reductions in both model subsets, which tend to be larger and more robust in CMIP5 LOW-r.

The tendency for a decrease in surface water availability in CMIP5 models, particularly CMIP5 LOW-r, implies an enhanced risk of CA drought. In contrast, the tendency for an increase in surface water availability in CMIP5 HIGH-r, particularly for central and northern $C A$, implies a muted risk of $C A$ drought under warming. However, even in CMIP5 HIGH-r, a decrease in surface water availability is projected during the non-winter months, particularly MAM and SON. 


\section{ANN SST \& ANN CA Soil Moisture}

\section{DJF SST \& JJA CA Soil Moisture} Observations

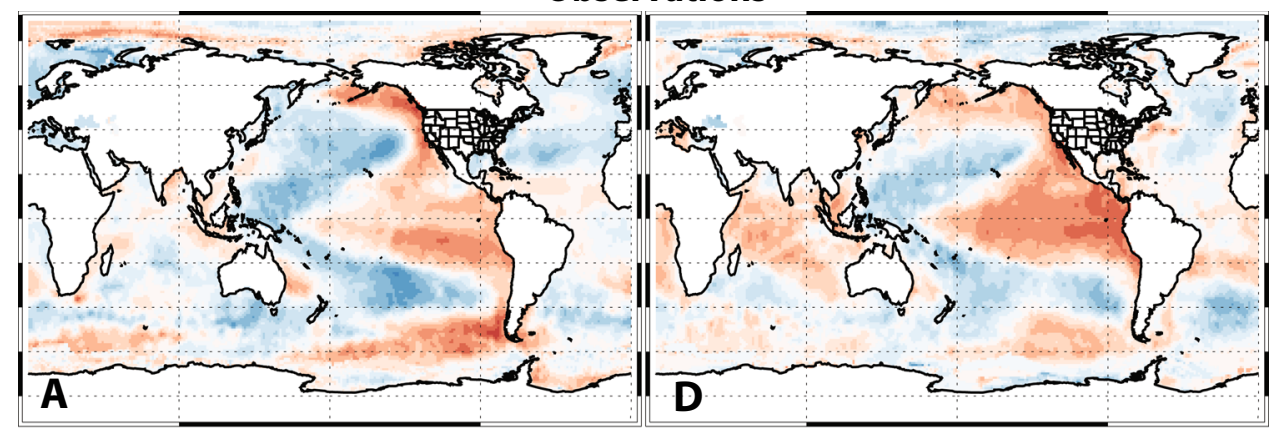

CMIP5 HIGH-r

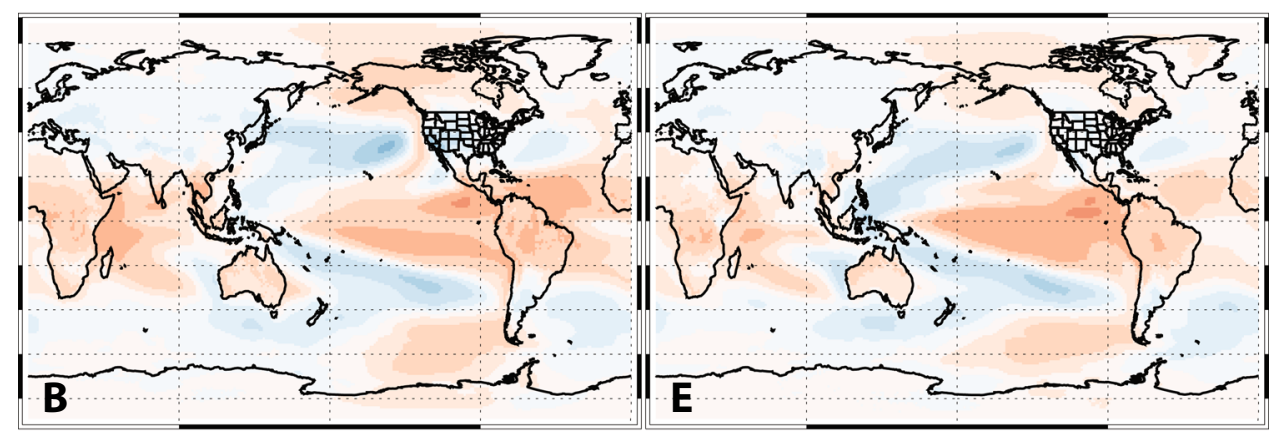

\section{CMIP5 LOW-r}

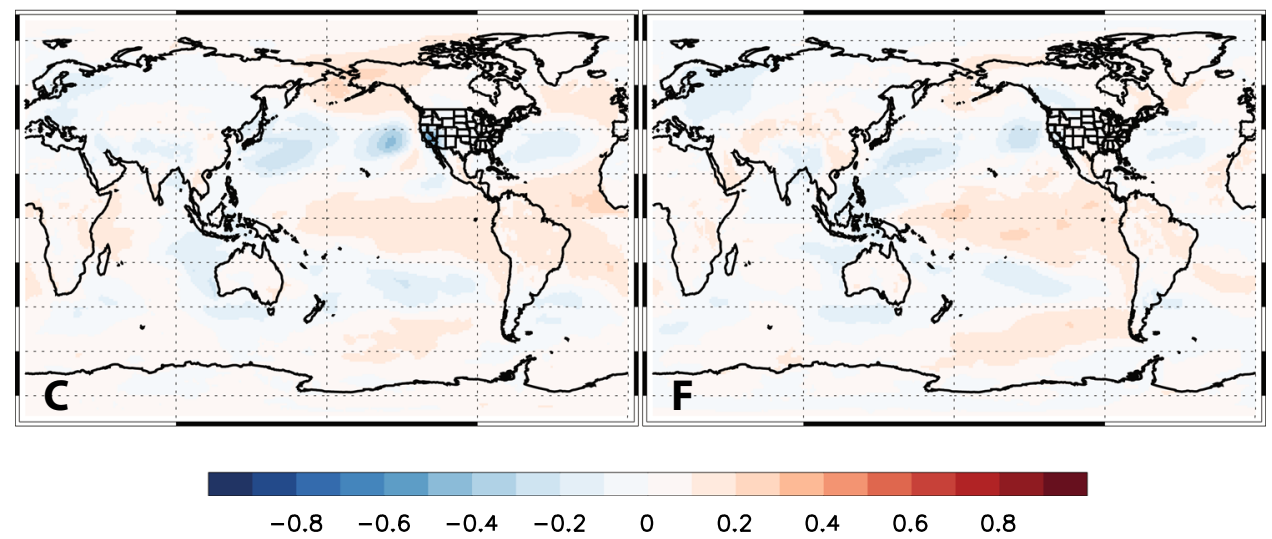

Fig. 1 Late-20th century correlation maps between California soil moisture and sea surface temperatures. Detrended correlations between (left panels) annual mean sea surface temperatures (SST) and annual mean California (CA) soil moisture; and (right panels) December-January-February (DJF) SSTs and the subsequent June-July-August (JJA) CA soil moisture for (top panels) observations; (middle panels) the model subset that yield a detrended DJF Niño 3.4 sea surface temperature versus California precipitation correlation of at least 0.30 (CMIP5 HIGH-r); and (bottom panels) the model subset that yields a corresponding correlation less than 0.20 (CMIP5 LOW-r). Soil moisture observations are from European Space Agency Climate Change Initiative (ESACCI) and HadISST is used for observed SSTs. All correlations are based on the 1950-1999 time period, except the ESACCl observed correlations, which span 1979-2015

Precipitation type and snowpack

Another important consideration for future changes in drought risk is how the type of precipitation (i.e., solid versus liquid) is projected to change. Consistent with the large future warming under RCP8.5, significant and robust decreases in CA solid precipitation (i.e., snowfall) are projected. The entire CMIP5 database yields a significant decrease of ANN solid precipitation at $-0.12 \mathrm{~mm} \mathrm{day}^{-1}$ century $^{-1}$, with $100 \%$ model realization agreement. CMIP5 $\mathrm{HIGH}-\mathrm{r}$ and LOW-r also yield significant decreases of -0.10 and $-0.15 \mathrm{~mm}^{\text {day }}{ }^{-1}$ century $^{-1}$, respectively, with $100 \%$ model realization agreement (Table 1).

For the entire CMIP5 database, the ensemble mean ANN increase in total (solid + liquid) precipitation is $0.06 \mathrm{~mm}$ day $^{-1}$ century $^{-1}$, and the decrease in solid precipitation is $-0.12 \mathrm{~mm}$ day $^{-1}$ century $^{-1}$. This yields a significant increase in liquid precipitation (i.e., rain) of $0.18 \mathrm{~mm} \mathrm{day}^{-1}$ century $^{-1}(76 \%$ realization agreement), three times larger than the increase in total precipitation. In the case of CMIP5 HIGH-r, the ensemble mean increase in (solid + liquid) precipitation is $0.16 \mathrm{~mm}$ day $^{-1}$ century $^{-1}$ and the decrease in solid precipitation is $-0.10 \mathrm{~mm}$ day $^{-1}$ century $^{-1}$. This yields a significant increase in liquid precipitation of $0.26 \mathrm{~mm}$ day $^{-1}$ century $^{-1} \quad(83 \%$ realization agreement), which is $\sim 60 \%$ larger than the increase in total precipitation. With CMIP5 LOW-r, where total and solid precipitation both decrease by $-0.15 \mathrm{~mm}^{\text {day }}{ }^{-1}$ century $^{-1}$, the change in liquid precipitation is negligible at $-0.006 \mathrm{~mm}_{\text {day }}{ }^{-1}$ century $^{-1}$ 
OBS

CMIP5 HIGH-r

CMIP5 LOW-r

Normalized ANN SST Pattern Associated with 5 Largest ANN CA Soil Moisture

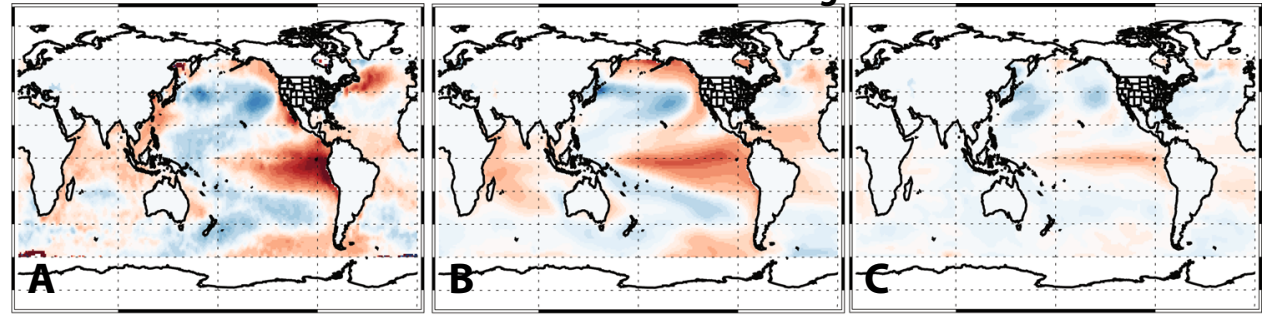

Normalized ANN SST Pattern Associated with 5 Smallest ANN CA Soil Moisture

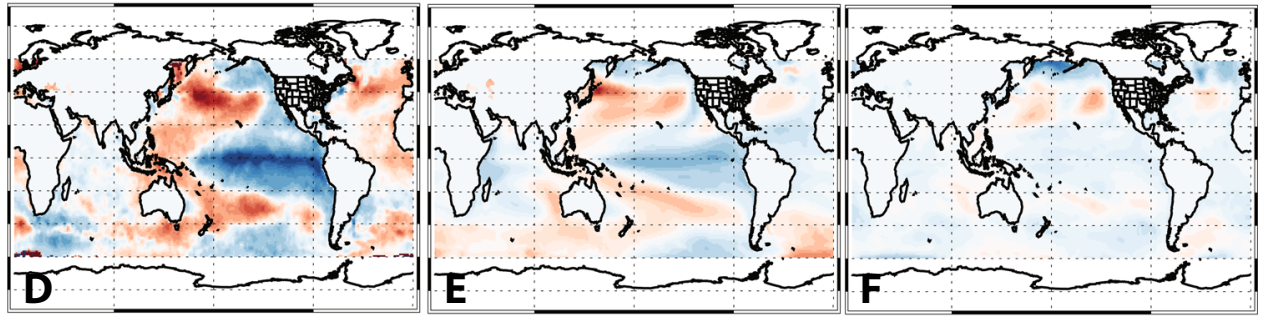

Normalized DJF SST Pattern Associated with 5 Largest JJA CA Soil Moisture

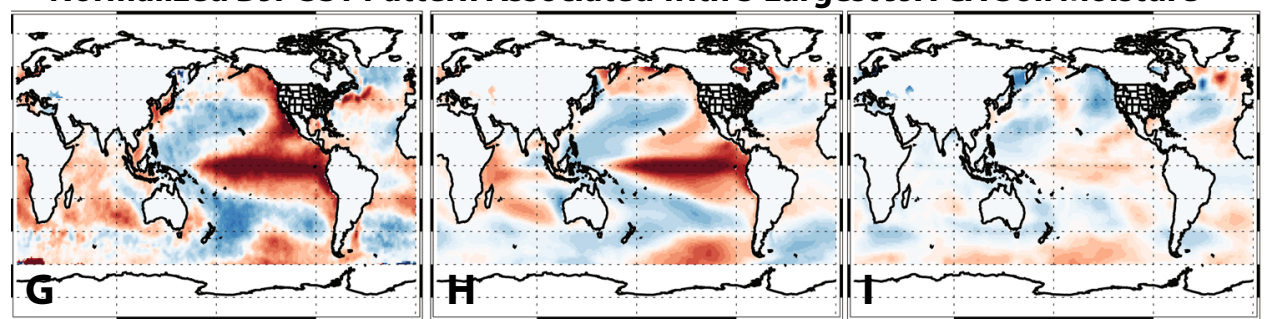

Normalized DJF SST Pattern Associated with 5 Smallest JJA CA Soil Moisture

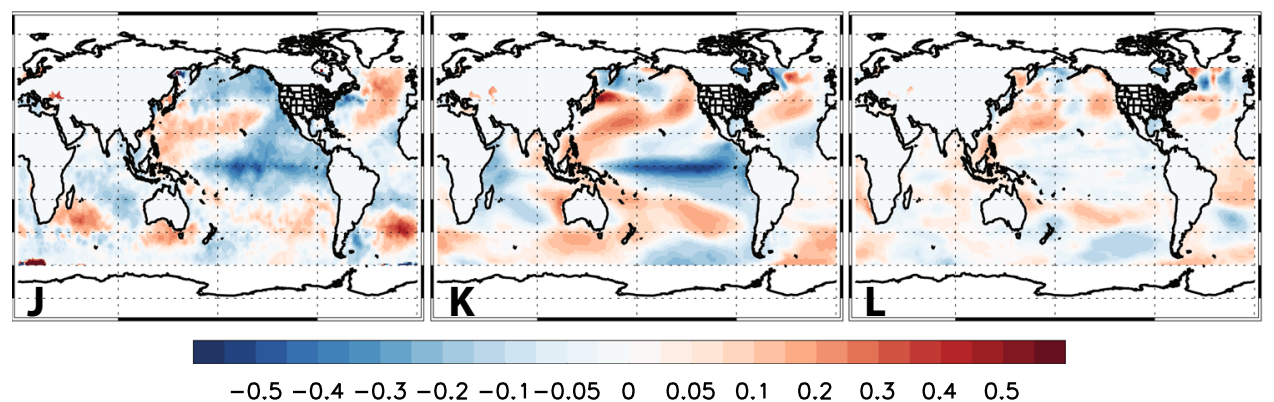

${ }^{\circ} \mathrm{C}$ per $\mathrm{cm}$

Fig. 2 Late-20th century sea surface temperature anomaly composite maps for the five largest and smallest California soil moisture anomalies. (Top panels) Annual mean sea surface temperature (SST) anomaly pattern associated with the five (a-c) largest and (d-f) smallest annual mean CA soil moisture anomalies for (left panels) observations; (middle panels) the model subset that yield a detrended DJF Niño 3.4 sea surface temperature versus California precipitation correlation of at least 0.30 (CMIP5 HIGH-r); and (right panels) the model subset that yields a corresponding correlation less than 0.20 (CMIP5 LOW-r). (Bottom panels) December-January-February (DJF) SST anomaly pattern associated with the subsequent June-July-August $(J J A)$ five $(\mathbf{g}-\mathbf{i})$ largest and $(\mathbf{j}-\mathrm{I})$ smallest CA soil moisture anomalies. SSTs are normalized by the absolute value of CA soil moisture. Soil moisture observations are from European Space Agency Climate Change Initiative (ESACCI) and HadISST is used for observed SSTs. All analyses are based on the 1950-1999 time period, except ESACCl, which span 1979-2015

(47\% realization agreement). Thus, models project a robust decrease in snowfall, and in turn, snowpack. Furthermore, in most models, especially CMIP5 HIGH-r, the proportion of precipitation falling as rain is projected to increase. This has implications for water storage systems that rely on the gradual melt of winter snow throughout the spring and early summer.

Change in Sierra snowpack is another important aspect of California climate change, and it has major impacts on hydrology. Consistent with prior studies, ${ }^{23,53-55}$ we find large and robust decreases in CA surface snow amount. For both CMIP5 HIGH-r and LOW-r, $100 \%$ of the realizations yield a negative 21 st century CA trend in surface snow amount based on the annual mean (Table
1), and all seasons, including MAM. In terms of the percent change in CA snow amount, defined as 2050-2099 minus the 1950-1999 climatology, divided by the 1950-1999 climatology, both model subsets yield similar CA percent changes, including -89 and $-90 \%$ based on annual means for CMIP5 HIGH-r and LOW-r, respectively. Similarly for MAM, the percent change in CA snow amount is $-94 \%$ for both model subsets. Thus, models project robust and large decreases in CA snowpack, and this is independent of the model subset. This again suggests continued caution is warranted regarding future changes in CA drought. 


\section{HIGH-r}
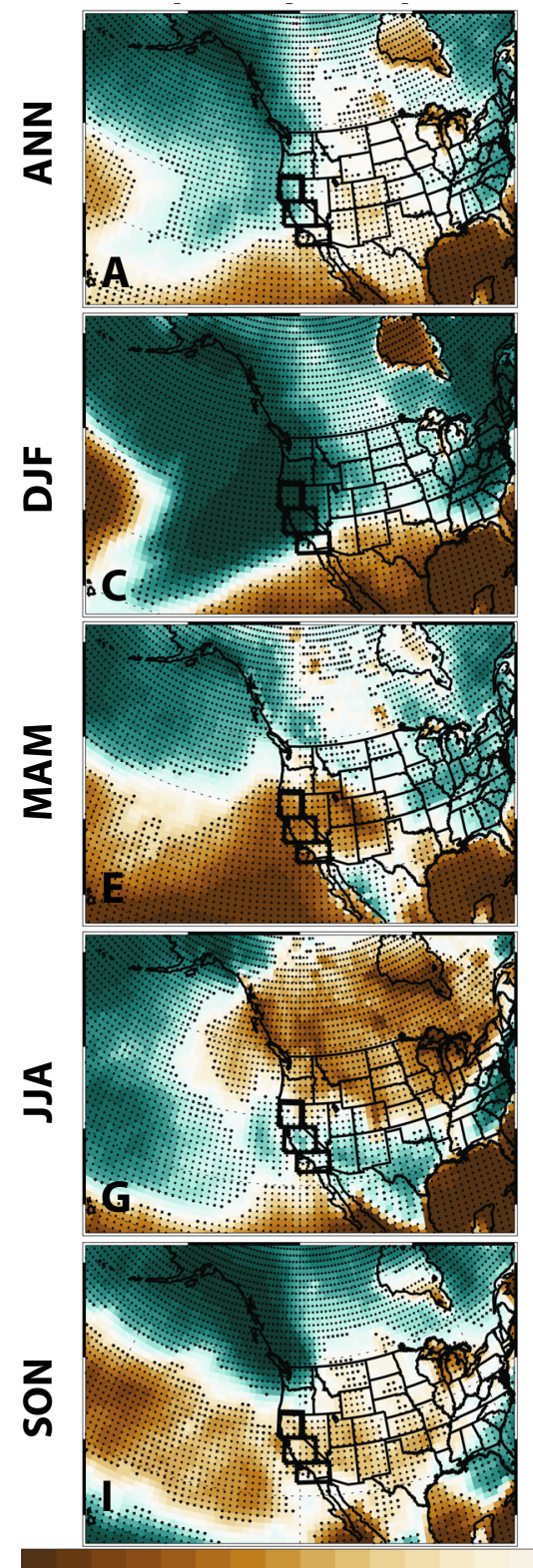

LOW-r
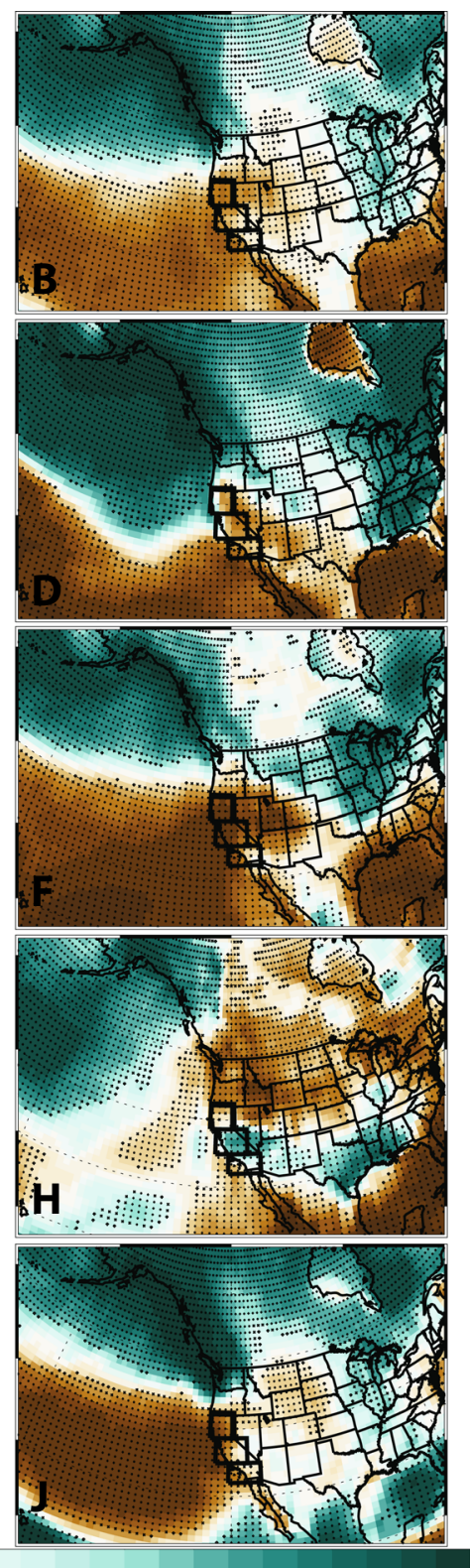

$\begin{array}{llllllllll}-0.5-0.4-0.3-0.2-0.15-0.1-0.05 & 0 & 0.05 & 0.1 & 0.15 & 0.2 & 0.3 & 0.4 & 0.5\end{array}$ [mm day ${ }^{-1}$ century $\left.{ }^{-1}\right]$

Fig. 3 Coupled Model Intercomparison Project version 5 RCP8.5 2006-2100 precipitation minus evapotranspiration trends Ensemble mean precipitation minus evapotranspiration (P-E) a, b Annual; c, d December-January-February; e, f March-April-May; $\mathbf{g}$, h June-July-August; i, $\mathbf{j}$ September-October-November mean trends $\left[\mathrm{mm}\right.$ day $^{-1}$ century ${ }^{-1}$ ] for two CMIP5 model subsets. Left panels show the model subset that yield a detrended DJF Niño 3.4 sea surface temperature versus California precipitation correlation of at least 0.30 (CMIP5 HIGH-r); Right panels show the model subset that yield a corresponding correlation less than 0.20 (CMIP5 LOW-r). Symbols represent trend significance at the $90 \%$ (diamond), 95\% (X) or 99\% (+) confidence level, accounting for autocorrelation. Blue/green (brown) colors represent an increase (decrease) in surface water availability. Also included are the three regions comprising California, denoted with thick black lines

\section{Land surface hydrology}

In addition to quantifying meteorological drought (i.e., changes in precipitation), hydrological and agricultural drought also exist. Hydrological drought is often quantified in terms of streamflow, ${ }^{56}$ whereas agricultural drought is quantified in terms of soil moisture. ${ }^{57}$ The entire CMIP5 database (32 models and 65 realizations archived total runoff) yields a significant increase in CA ANN runoff of $0.05 \mathrm{~mm}^{\text {day }}{ }^{-1}$ century $^{-1}$, with $60 \%$ model realization agreement (Table 1). Figure 4 shows that the increase in CA total runoff is more robust and larger in CMIP5 HIGH-r, with an ensemble mean ANN increase of $0.13 \mathrm{~mm}$ day $^{-1}$ century $^{-1}$ and $73 \%$ model realization agreement. In contrast, CMIP5 LOW-r yields the opposite response-CA ANN runoff decreases by $-0.18 \mathrm{~mm}$ day $^{-1}$ century $^{-1}$, with $78 \%$ model realization agreement. These changes in runoff are consistent with the corresponding changes in precipitation.

Similar results are obtained for regional CA runoff changes (Supplementary Table 2). CMIP5 LOW-r models yield significant reductions in each region, with larger reductions from south to north. CMIP5 HIGH-r yields nonsignificant runoff increases in 


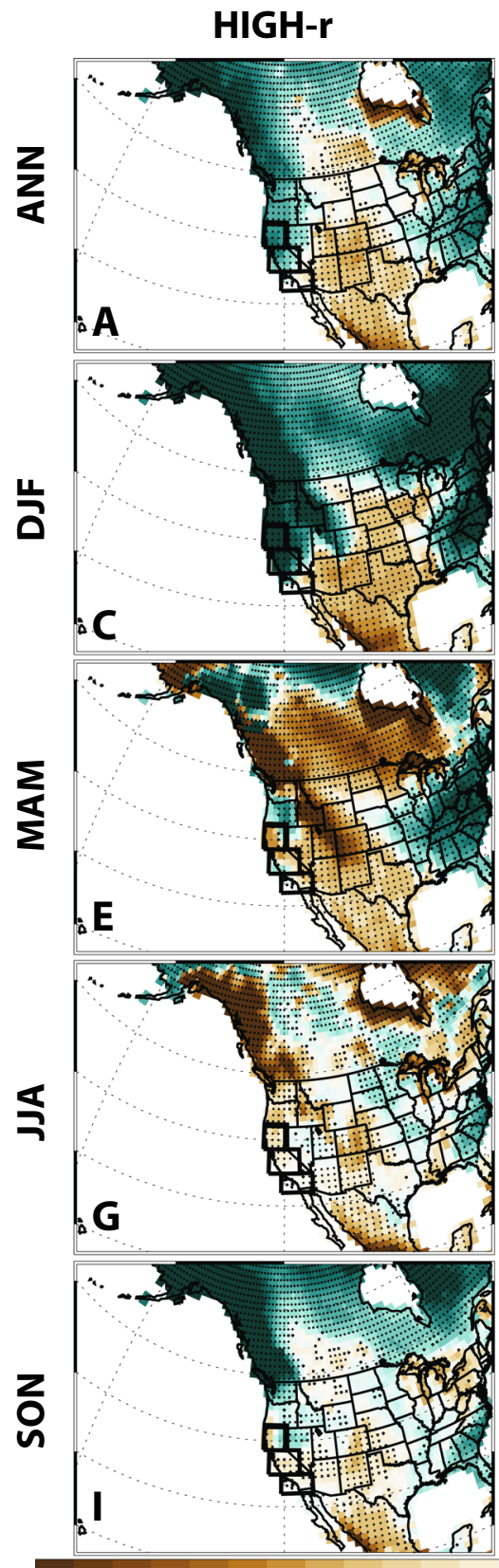

LOW-r
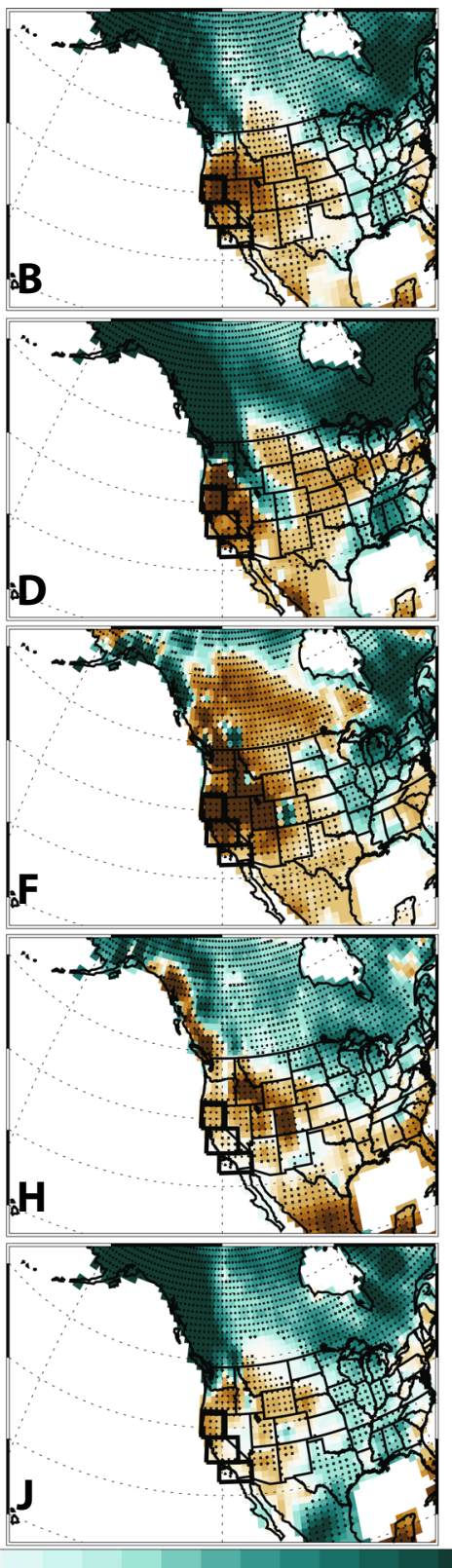

0.020 .04

0.1

$\begin{array}{lll}2 & 0.3 & 0.4\end{array}$

[mm day ${ }^{-1}$ century $\left.{ }^{-1}\right]$

Fig. 4 Coupled Model Intercomparison Project version 5 RCP8.5 2006-2100 total runoff trends. Ensemble mean total runoff a, b Annual; c, $\mathbf{d}$ December-January-February; e, f March-April-May; $\mathbf{g}, \mathbf{h}$ June-July-August; $\mathbf{i}$, $\mathbf{j}$ September-October-November mean trends $\left[\mathrm{mm}\right.$ day ${ }^{-1}$ century $^{-1}$ ] for two CMIP5 model subsets. Left panels show the model subset that yield a detrended DJF Niño 3.4 sea surface temperature versus California precipitation correlation of at least 0.30 (CMIP5 HIGH-r); Right panels show the model subset that yield a corresponding correlation less than 0.20 (CMIP5 LOW-r). Symbols represent trend significance at the $90 \%$ (diamond), $95 \%(X)$ or $99 \%(+)$ confidence level, accounting for autocorrelation. Blue/green (brown) colors represent an increase (decrease) in total runoff. Also included are the three regions comprising California, denoted with thick black lines

southern CA, with significant increases of $0.13 \mathrm{~mm}$ day $^{-1}$ century $^{-1}$ in central CA and $0.26 \mathrm{~mm}^{\text {day }}{ }^{-1}$ century $^{-1}$ in northern CA. Thus, CMIP5 LOW-r models imply a reduction in streamflow and an enhanced risk of hydrological drought. CMIP5 HIGH-r models, however, imply the opposite response.

As with the other hydrological metrics, however, the increase in runoff in CMIP5 HIGH-r models primarily occurs during DJF (Table 1; Fig. 4). CMIP5 HIGH-r yields a significant increase in DJF CA P-E of $0.57 \mathrm{~mm}$ day $^{-1}$ century $^{-1}$, with $90 \%$ realization agreement. In contrast, CMIP5 LOW-r yields a nonsignificant decrease of $-0.27 \mathrm{~mm} \mathrm{day}^{-1}$ century $^{-1}$ (67\% realization agreement). Nonwinter seasons generally feature runoff reductions in both model subsets, which tend to be larger and more robust in CMIP5 LOW-r. For example, during MAM, CMIP5 HIGH-r (CMIP5 LOW-r) yields a nonsignificant (significant) decrease of $-0.03(-0.36) \mathrm{mm} \mathrm{day}^{-1}$ century $^{-1}$ with $57 \%(100 \%)$ realization agreement.

Agricultural drought is quantified using both shallow $(\sim 0-0.25 \mathrm{~m})$ and deep $(\sim 1.5-3 \mathrm{~m})$ soil moisture (Supplementary 


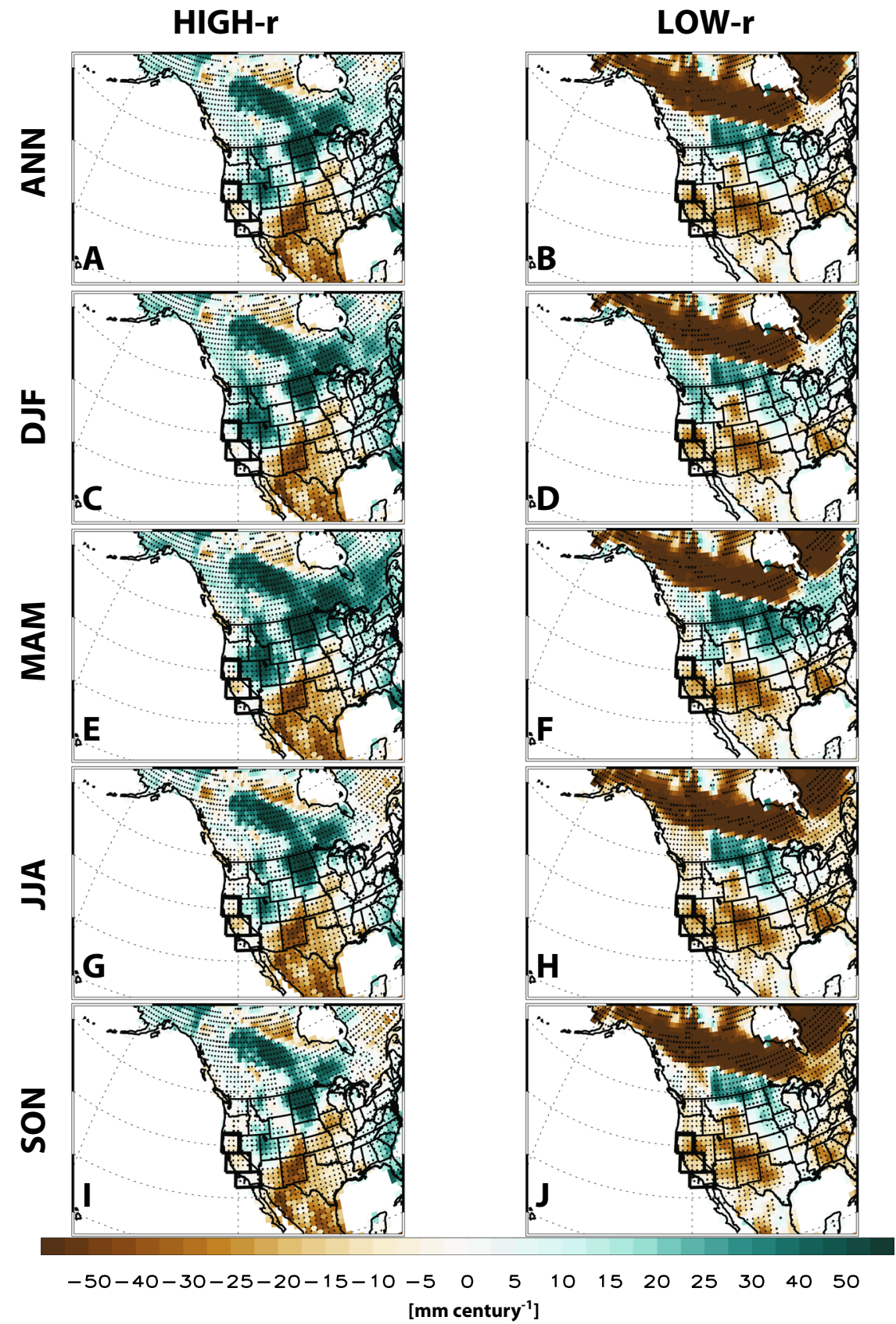

Fig. 5 Coupled Model Intercomparison Project version 5 RCP8.5 2006-2100 deep soil moisture trends. Ensemble mean deep (1.5-3 m) soil moisture a, b Annual; c, d December-January-February; e, f March-April-May; $\mathbf{g}$, h June-July-August; $\mathbf{i}$, j September-October-November mean trends [mm century ${ }^{-1}$ ] for two CMIP5 model subsets. Left panels show the model subset that yield a detrended DJF Niño 3.4 sea surface temperature versus California precipitation correlation of at least 0.30 (CMIP5 HIGH-r); Right panels show the model subset that yield a corresponding correlation less than 0.20 (CMIP5 LOW-r). Symbols represent trend significance at the 90\% (diamond), 95\% (X) or 99\% (+) confidence level, accounting for autocorrelation. Blue/green (brown) colors represent an increase (decrease) in deep soil moisture. Also included are the three regions comprising California, denoted with thick black lines

Table 3). Of the two, deep soil moisture is most relevant for agricultural impacts, as the deeper layer controls moisture supply for most deeper rooted, perennial CA plants and crops (Supplementary Discussion). Deep soil moisture (SMB) shows a significant ensemble annual mean decrease using all CMIP5 models (27 models and 51 realizations), at $-4.6 \mathrm{~mm}$ century $^{-1}$, with $61 \%$ realization agreement (Table 1). Figure 5 shows that CMIP5 HIGH-r yields a weaker and nonsignificant decrease at $-2.4 \mathrm{~mm}$ century $^{-1}$ with low realization agreement at $43 \%$ (i.e., the majority of the trends are actually positive). CMIP5 LOW-r yields a larger and more robust decrease, at $-9.7 \mathrm{~mm}$ century $^{-1}$ with $92 \%$ realization agreement. An SMB decrease exists for each subregion, with CMIP5 LOW-r yielding trends of $-4.1,-12.5$, and $-11.7 \mathrm{~mm}$ century $^{-1}$ for southern, central and northern CA (all significant at the $99 \%$ confidence level), with realization agreements of $92 \%$ for each subregion. CMIP5 HIGH-r yields corresponding trends of $0.2,-4.8$, and $-1.9 \mathrm{~mm}^{\text {century }}{ }^{-1}$ for southern, central and northern CA, with central CA yielding the lone significant trend (Supplementary Table 2). Corresponding model realization agreements continue to remain low at 47,43 , and $43 \%$, respectively. Thus, CMIP5 LOW-r yields robust decreases in CA deep soil moisture, implying enhanced risk of agricultural 


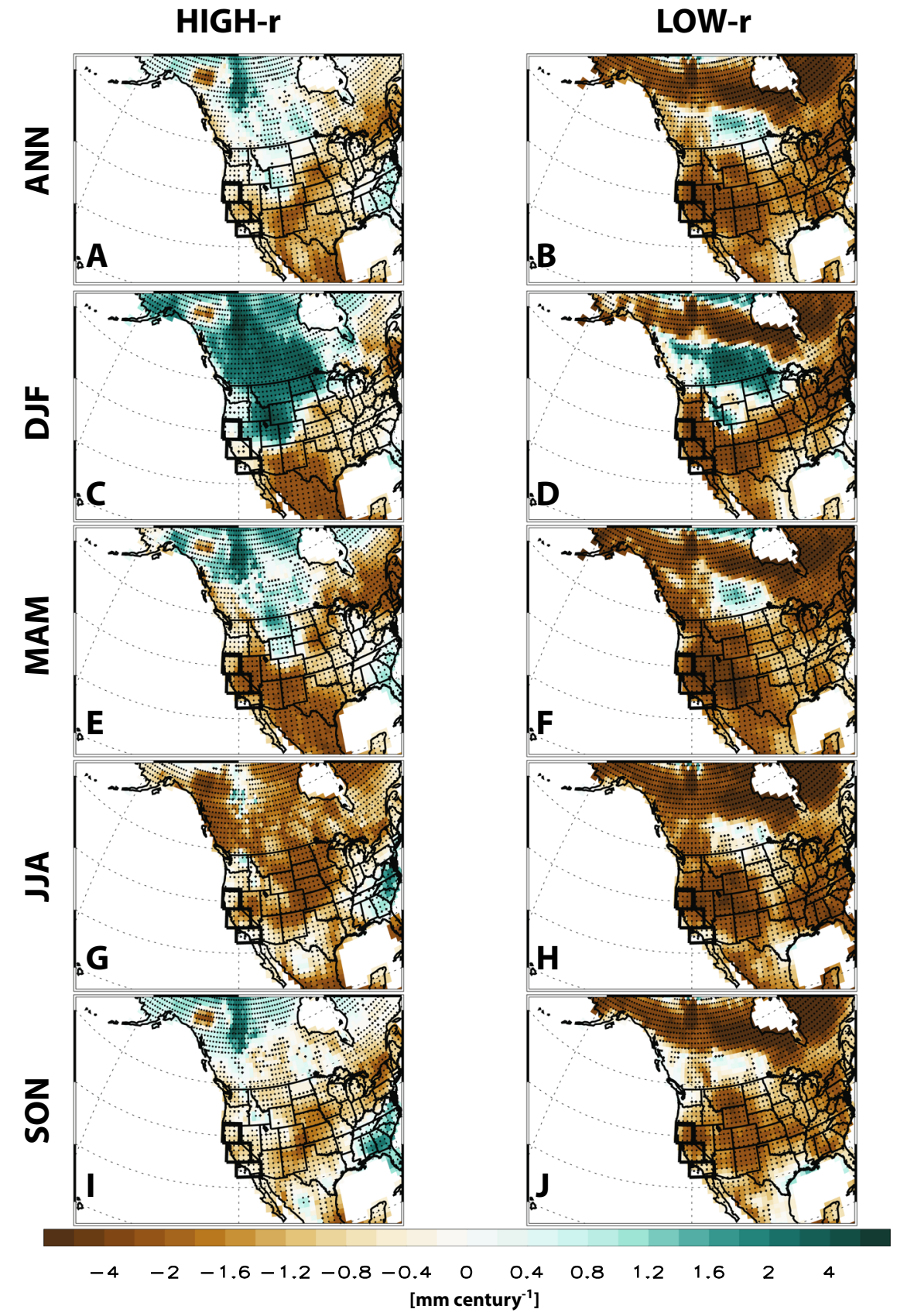

Fig. 6 Coupled Model Intercomparison Project version 5 RCP8.5 2006-2100 shallow soil moisture trends. Ensemble mean shallow (0-0.25 m) soil moisture a, b Annual; c, d December-January-February; e, f March-April-May; $\mathbf{g}$, h June-July-August; i, j September-October-November mean trends [mm century ${ }^{-1}$ ] for two CMIP5 model subsets. Left panels show the model subset that yield a detrended DJF Niño 3.4 sea surface temperature versus California precipitation correlation of at least 0.30 (CMIP5 HIGH-r); Right panels show the model subset that yield a corresponding correlation less than 0.20 (CMIP5 LOW-r). Symbols represent trend significance at the $90 \%$ (diamond), $95 \%$ (X) or $99 \%$ ( + ) confidence level, accounting for autocorrelation. Blue/green (brown) colors represent an increase (decrease) in shallow soil moisture. Also included are the three regions comprising California, denoted with thick black lines

drought. CMIP5 HIGH-r yields weaker decreases in SMB, with minimal realization agreement.

Seasonally, the CMIP5 HIGH-r models yield a nonsignificant increase in CA SMB during DJF (Table 1; Fig. 5) of $1.3 \mathrm{~mm}$ century $^{-1}$, with $62 \%$ realization agreement. In contrast, CMIP5 LOW-r yields significant a decrease of $-11.0 \mathrm{~mm}^{\text {century }}{ }^{-1}(92 \%$ realization agreement). Non-winter seasons generally feature SMB reductions in both model subsets, which tend to be larger and more robust in CMIP5 LOW-r. For example, during JJA, CMIP5 HIGH-r (CMIP5 LOW-r) yields a significant decrease of $-4.5(-9.7)$ $\mathrm{mm}$ century $^{-1}$ with $48 \%$ (92\%) realization agreement.
Figure 6 shows that shallow soil moisture (SMT) is also projected to decrease, and these changes are more robust relative to changes in deep soil moisture. CMIP5 models yield a significant SMT decrease of $-0.92 \mathrm{~mm}$ century $^{-1}$ with $80 \%$ realization agreement. All three regions yield a significant decrease in SMT at $-0.74,-1.0$, and $-0.94 \mathrm{~mm}$ century ${ }^{-1}$ for southern, central and northern CA, with 82,80 , and $75 \%$ realization agreement, respectively. CMIP5 LOW-r yields a stronger and more robust decrease at $-1.6 \mathrm{~mm}$ century $^{-1}$ with $100 \%$ model realization agreement. CMIP5 HIGH-r yields a decrease of $-0.6 \mathrm{~mm}$ century $^{-1}$ with $62 \%$ model realization agreement. Both model subsets yield 
significant SMT decreases for each CA region, with larger realization agreement in CMIP5 LOW-r (Supplementary Table 2).

Seasonal SMT results show that CMIP5 HIGH-r (LOW-r) models yield non-significant (significant) negative trends during DJF (Table 1; Fig. 6), with low (high) realization agreement. Nonwinter seasons generally feature significant SMT reductions in both model subsets, which tend to be larger and more robust in CMIP5 LOW-r. For example, during JJA, CMIP5 HIGH-r (CMIP5 LOW-r) yields a significant decrease of $-0.52(-1.37) \mathrm{mm}$ century $^{-1}$ with $52 \%$ (83\%) realization agreement.

The decrease in soil moisture is consistent with the decrease in surface water availability, particularly in CMIP5 LOW-r. In CMIP5 HIGH-r, despite an increase in surface water availability, soil moisture-particularly near the surface-still decreases. This is likely due to the change in precipitation, with more rain instead of snow-the increase in surface water is not able to be absorbed into the soil, and instead runs off. Furthermore, the more robust decrease in near-surface soil moisture, as opposed to deep soil moisture, is consistent with the importance of enhanced evaporation due to warming in dictating changes in nearsurface soil moisture. ${ }^{22}$ In contrast, deeper soil moisture responds most sensitively to changes in precipitation, which also helps to explain the robust SMB decrease in CMIP5 LOW-r (where precipitation decreases), but weaker SMB change in CMIP5 HIGH-r (where precipitation increases).

\section{California annual and multi-annual drought risk}

Figure 7 shows the enhanced risk of CA annual drought (Methods; a $-0.5 \sigma$ departure from the 1950-1999 baseline) based on several metrics, including surface water availability $(\mathrm{P}-\mathrm{E})$, precipitation $(\mathrm{P})$, runoff, shallow (SMT) and deep soil moisture (SMB). CMIP5 models show enhanced annual drought risk for all metrics, ranging from modest (but still generally significant) increases based on $P-E, P$ and runoff (3-8\%), to more substantial increases based on SMB $(12.8 \%)$ and SMT (26.1\%). The enhanced drought risk based on SMB represents an increased probability of drought from $34.2 \%$ at the end of the 20th century, to $47.0 \%$ at the end of the $21 \mathrm{st}$ century (Supplementary Table 4). Much of the enhanced drought risk comes from CMIP5 LOW-r models, which yield significant increases in drought risk for all metrics. Based on $P-E, P$, and runoff, CMIP5 LOW-r yields enhanced CA drought risks of 22.4, 12.8 , and $28.2 \%$, respectively. Based on soil moisture metrics, the enhanced drought risk is larger, at $29.4 \%$ for SMB and $42.6 \%$ for SMT. The enhanced drought risk based on SMB represents nearly a doubling of the probability of drought, from $34.3 \%$ at the end of the 20 th century, to $63.7 \%$ at the end of the 21 st century (Supplementary Table 4).

In contrast, CMIP5 HIGH-r models yield a muted, and generally non-significant, change in $C A$ annual drought risk. Based on $P-E, P$ and runoff, the change in annual drought risk is $0.3,-2.1$, and $1.3 \%$, respectively. For soil moisture metrics, the values are larger-particularly for surface soil moisture-but considerably smaller than those based on CMIP5 and in particular, CMIP5 LOW-r, at 3.4\% for SMB and $16.7 \%$ for SMT.

Similar results are obtained based on multi-annual (3 year) drought (Fig. 7b; Supplementary Table 5) and more severe (Methods; $a=-1.0 \sigma$ departure from the 1950-1999 baseline) drought (Supplementary Fig. 10; Supplementary Table 6). Thus, similar conclusions apply for the duration and intensity of drought, in addition to the frequency. We have also verified that the change in drought risk is similar when based on the SPI (Supplementary Discussion; Supplementary Fig. 11).

These results are consistent with the prior discussion that showed CMIP5 LOW-r tends to yield decreases in precipitation, surface water availability, runoff and soil moisture. In contrast, CMIP5 HIGH-r generally yields the opposite responses, particularly for $\mathrm{P}, \mathrm{P}-\mathrm{E}$, and runoff. The main exception is soil moisture,
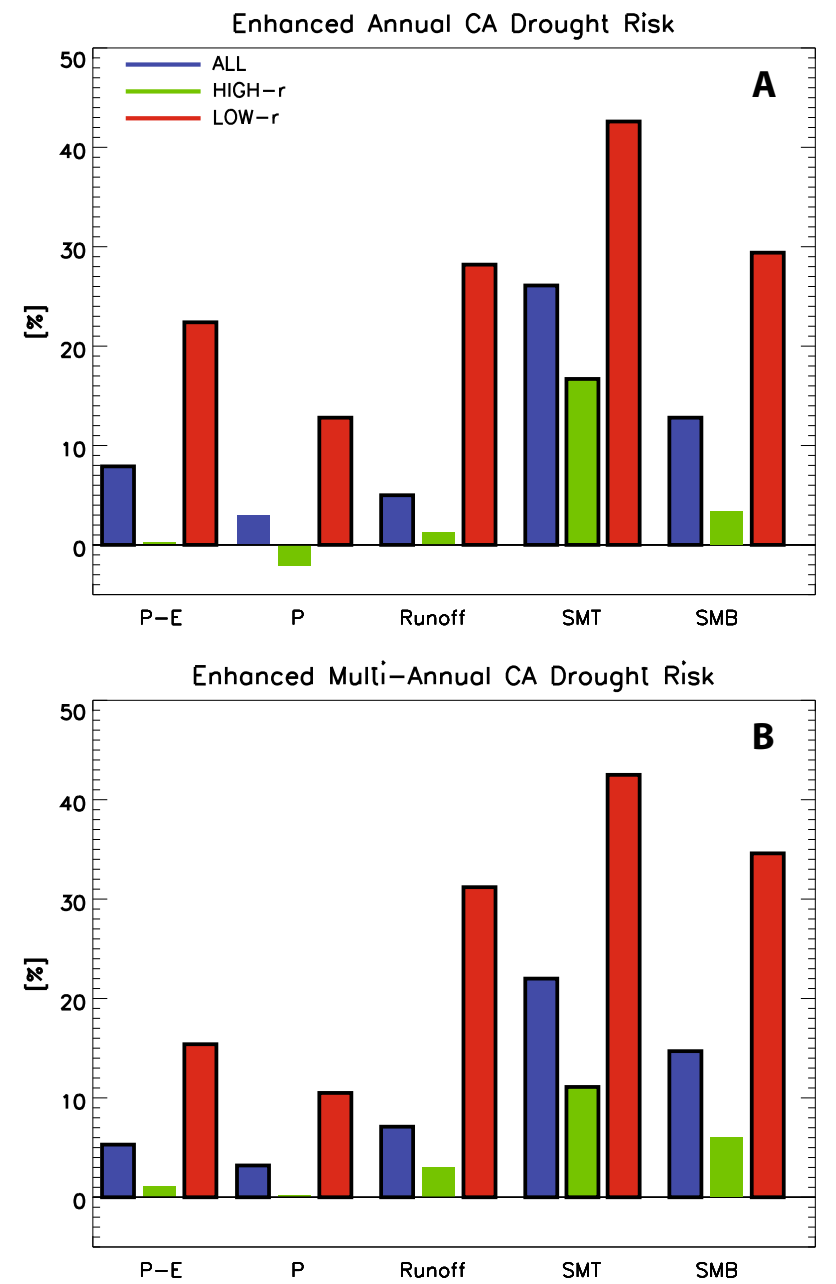

Fig. 7 Coupled Model Intercomparison Project version 5 RCP8.5 enhanced California drought risk. Ensemble mean (a) annual and (b) multi-annual (3-year) California drought risk [\%] based on precipitation minus evapotranspiration $(P-E)$, precipitation $(P)$, runoff, shallow $(0-0.25 \mathrm{~m})$ soil moisture $(\mathrm{SMT})$ and deep $(1.5-3 \mathrm{~m})$ soil moisture (SMB). Colored bars show the ensemble mean enhanced drought risk based on all CMIP5 models (blue; ALL), the model subset that yields a detrended DJF Niño 3.4 sea surface temperature versus California precipitation correlation of at least 0.30 (green; HIGH-r), and the model subset that yields a corresponding correlation less than 0.20 (red; LOW-r). Bars with a thick black outline indicates significance at the $95 \%$ confidence level, based on a standard $t$-test

particularly SMT, with CMIP5 HIGH-r models yielding relatively large and significant increases in SMT drought at $16.7 \%$. This is consistent with the strong sensitivity of drying of the upper soil to enhanced evaporation due to warming, as opposed to changes in precipitation. However, in the context of agricultural drought, the deep soil moisture is most relevant for agricultural impacts (Supplement), since the deeper layer controls the moisture availability for most California plants and non-vegetable crops. ${ }^{22}$ CMIP5 HIGH-r yields a non-significant increase in SMB drought at $3.4 \%$, suggested minimal change in the risk of agricultural drought.

The results are robust to the criteria used to define CMIP5 $\mathrm{HIGH}-\mathrm{r}$ and LOW-r models. For example, re-defining the HIGH-r (LOW-r) models as those with a late 20th century DJF CA precipitation versus Niño 3.4 SST regression coefficient within one sigma (less than 1 sigma) of observations ${ }^{27}$ leads to similar conclusions. CMIP5 HIGH-r continues to yield a negligible increase in CA drought risk (Supplementary Fig. 12). 
Finally, an alternative "HIGH-r" model subset is defined that satisfies multiple criteria: 1 . late-20th and 21st century correlations between DJF CA precipitation and Niño 3.4 SSTs are significant at the $90 \%$ confidence level; 2 . late-20th century DJF CA precipitation versus Niño 3.4 SST regression coefficient falls within 1-sigma of the observed range; and 3. late-20th century DJF CA precipitation climatologies fall within 1-sigma of the observed range. These criteria result in three models, with 12 realizations. As with the other methods used to define HIGH-r models, minimal increase in CA drought risk exists in this model subset (Supplementary Fig. 12). Thus, models that better simulate $C A$ precipitation statistics yield negligible change in CA drought risk.

Regionally, a larger increase in annual meteorological drought risk exists in southern $C A$, based on $P$ and $P-E$ (Supplementary Fig. 13). This is consistent with a decrease in both $P$ and $P-E$ in southern CA for all model subsets. Moreover, CMIP5 LOW-r yields the largest enhanced meteorological drought risk in southern $C A$, consistent with the maximum decrease in southern CA P and P-E in this model subset. In central and northern CA, based on CMIP5 $\mathrm{HIGH}-\mathrm{r}$, the annual meteorological drought risk generally decreases, particularly for northern CA, where P-E and particularly $P$ indicate decreased drought risk. This, too, is consistent with the increase in $\mathrm{P}$ and $\mathrm{P}-\mathrm{E}$ in central, and particularly, northern $\mathrm{CA}$ in CMIP5 HIGH-r.

Based on soil moisture metrics, each region is projected to experience an increased risk of agricultural drought, independent of model subset, with the smallest increase in CMIP5 HIGH-r. Moreover, CMIP5 HIGH-r continues to yield non-significant increases in drought risk based on deep soil moisture. The increase in SMB drought risk is relatively similar for all three regions, although there is a weak south to north decrease in the enhanced risk. For example, CMIP5 yields an increase in SMB drought risk of $18.5,14.1$, and $10.2 \%$ from south to north, which is consistent with the corresponding change in precipitation, and the importance of $P$ in driving changes in deep soil moisture. In other words, regions that receive a larger increase (decrease) in precipitation-including central and northern CA (southern CA)-yield a weaker (stronger) increase in drought risk based on deep soil moisture. Compared to SMB, the drought risk based on shallow soil moisture shows the opposite gradient-an increase
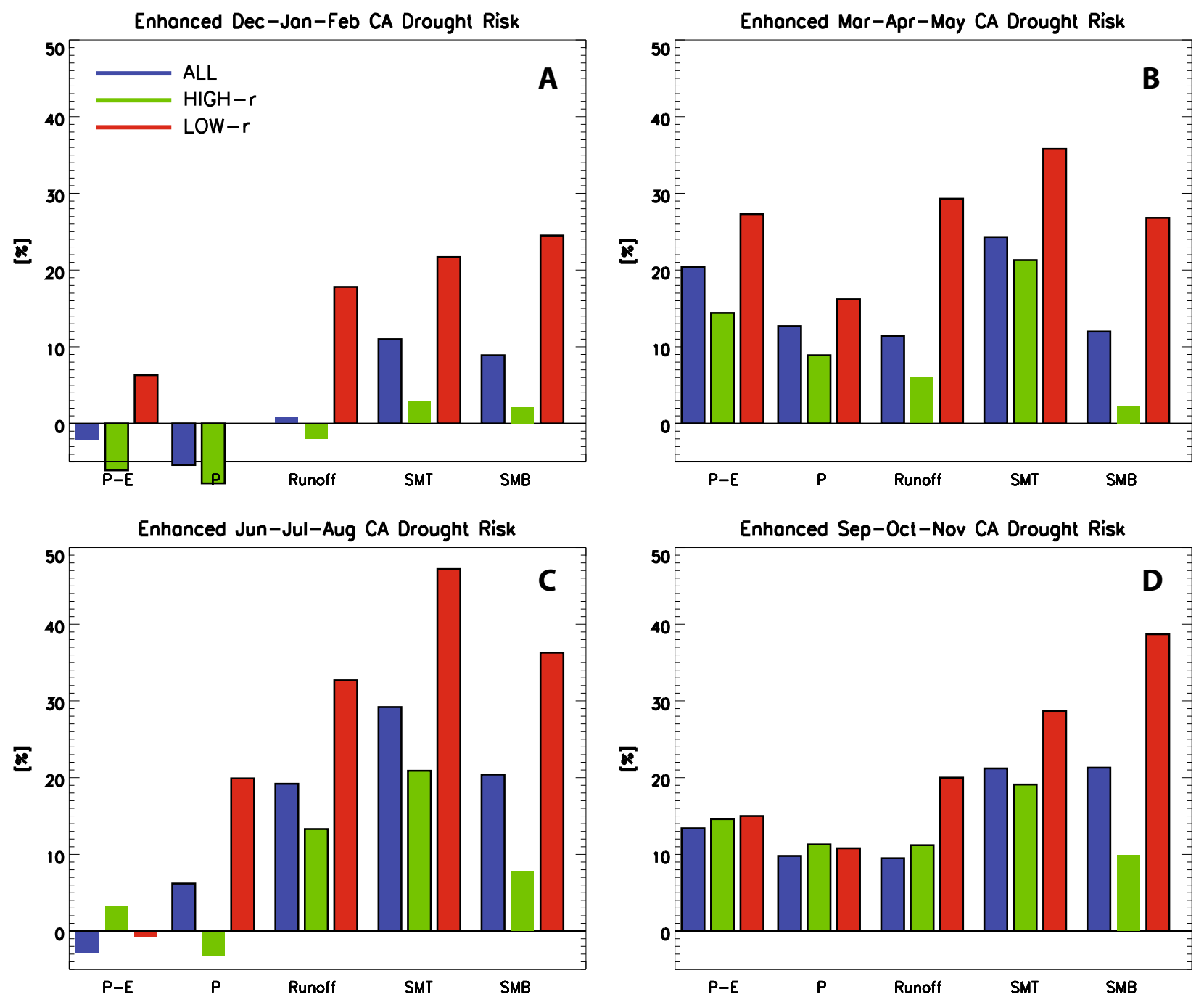

Fig. 8 Coupled Model Intercomparison Project version 5 RCP8.5 enhanced seasonal California drought risk. Ensemble mean a December-January-February (DJF); b March-April-May (MAM); c June-July-August (JJA); and d September-October-November (SON) California drought risk [\%] based on precipitation minus evapotranspiration (P-E), precipitation (P), runoff, shallow (0-0.25 m) soil moisture (SMT) and deep (1.5-3 m) soil moisture (SMB). Colored bars show the ensemble mean enhanced drought risk based on all CMIP5 models (blue; All), the model subset that yields a detrended DJF Niño 3.4 sea surface temperature versus California precipitation correlation of at least 0.30 (green; $\mathrm{HIGH}-\mathrm{r}$ ), and the model subset that yields a corresponding correlation less than 0.20 (red; LOW-r). Bars with a thick black outline indicates significance at the $95 \%$ confidence level, based on a standard $t$-test 
from south to north. For example, CMIP5 yields an increase in SMT drought risk of $20.8,20.3$, and $28.7 \%$ from south to north. This is consistent with the importance of evapotranspiration in dominating the SMT response, as $E$ increases from $0.07 \mathrm{~mm}$ day $^{-1}$ century $^{-1}$ in southern and central CA to $0.10 \mathrm{~mm} \mathrm{day}^{-1}$ century $^{-1}$ in northern CA.

Similar results are obtained using alternative RCPs, including RCP4.5 (Supplementary Fig. 14) and RCP6.0 (Supplementary Fig. 15). Generally, a smaller increase in drought risk occurs under scenarios with less end of the century radiative forcing (e.g., RCP4.5 versus RCP8.5), but the difference between CMIP5 HIGH-r and LOW-r remains. CMIP5 LOW-r models yield the largest increase in CA drought risk, particularly based on soil moisture metrics (both deep and shallow). CMIP5 HIGH-r yields much weaker increases, especially based on meteorological and hydrological drought. The largest increase of CA drought risk in CMIP5 HIGH-r models continues to be with the SMT metric. However, deep soil moisture, which is most important for agricultural drought, does not significantly increase in any RCP under CMIP5 $\mathrm{HIGH}-\mathrm{r}$.

\section{California seasonal drought risk}

As described above, the bulk of the wettening trend in CMIP5 HIGH-r occurs during DJF. Non-winter seasons generally feature drying trends in both model subsets, which tend to be larger and more robust in CMIP5 LOW-r. This shift in seasonal precipitation implies a shortening of the wet season, which could stress water resources and ecosystems, irrespective of changes in the annual mean.

Figure 8 shows seasonal changes in CA drought risk for surface water availability $(\mathrm{P}-\mathrm{E})$, precipitation $(\mathrm{P})$, runoff, shallow $(\mathrm{SMT})$ and deep soil moisture $(\mathrm{SMB})$. Consistent with the relatively large increase in DJF CA precipitation in CMIP5 HIGH-r models, DJF CA drought risk is generally reduced. CMIP5 LOW-r models, however, still yield a significant increase in DJF CA drought for most metrics. During SON, models yield a significant increase in CA drought risk, including CMIP5 HIGH-r models (except based on SMB). CMIP5 LOW-r models yield the largest increase in SON CA drought risk, particularly based on hydrologic (runoff) and agricultural (SMT and SMB) metrics. During MAM, models also generally yield a significant increase in drought. All CMIP5 models show that this season experiences the largest increase in meteorological drought ( $\mathrm{P}$ and $\mathrm{P}-\mathrm{E}$ ), particularly in CMIP5 LOW-r models. CMIP5 HIGH-r also yields significant increases in MAM drought based on $\mathrm{P}, \mathrm{P}-\mathrm{E}$ and SMT, but less than that in other models. MAM drought in CMIP5 HIGH-r models based on both runoff and SMB, however, yield non-significant increases. During summer (JJA), meteorological drought is generally muted, except in CMIP5 LOW-r models based on precipitation. However, models show a significant increase in hydrological and agricultural drought, which is again largest in CMIP5 LOW-r models. Consistent with the other seasons, CMIP5 HIGH-r models yield non-significant increases in SMB.

Thus, although the increase in annual and multi-annual CA drought is muted in CMIP5 HIGH-r models, significant increases still occur in the dry season, particularly MAM and SON for most metrics. These results imply continued concern is warranted regarding future CA drought risk. The wintertime increase in precipitation and other hydrological variables in CMIP5 $\mathrm{HIGH}-\mathrm{r}$ models implies adaptation measures focused on smoothing seasonal differences for affected agricultural, terrestrial, and aquatic systems, as well as effectively capturing enhanced winter runoff, to alleviate possible drought increases during the dry season.

\section{DISCUSSION}

Building off previous work, ${ }^{27}$ CMIP5 models that better simulate the observed correlation between CA precipitation and EI Niño interannual variability yield larger and more consistent increases in California precipitation, surface water availability and runoff under global warming, with relatively small changes in soil moisture (particularly SMB). This, in turn, translates into negligible change in the risk of annual and multi-annual CA drought under warming. In contrast, models that poorly simulate the observed $\mathrm{El}$ Niño-CA precipitation teleconnection yield significant enhancement of drought risk, for all five drought metrics, for CA and each of the three subregions. This is consistent with projected reductions in surface water availability, runoff, and soil moisture. Similar conclusions are obtained when additional criteria are used to subsample the models, including the ability to simulate CA precipitation climatologies, and the observed sensitivity of CA precipitation to El Niño variations.

With CMIP5 HIGH-r, the lone exception is the shallow soil moisture estimate of drought, which is projected to significantly increase. This is consistent with the strong sensitivity of drying of the upper soil to enhanced evaporation due to warming, as opposed to changes in precipitation. However, in the context of agricultural drought, the deep soil moisture is most important, since the deeper layer controls the moisture availability for most California plants and non-vegetable crops. Although this model subset suggests a muted risk of enhanced annual and multiannual CA drought, it does suggest an increased risk of flooding. This is due to several factors, including an increase in precipitation, as well as an increase in the proportion of precipitation falling as rain, as opposed to snow. Consistently, runoff is projected to increase. These changes are generally largest in central and northern $C A$, and muted in southern CA.

On a seasonal basis, CMIP5 HIGH-r yields significant increases in CA drought risk for several metrics during the dry season. This is related to shortening of the wet season, which could stress water resources and ecosystems, irrespective of changes in the annual mean. Furthermore, both model subsets project large and robust decreases in Sierra snowpack. Thus, continued concern is warranted regarding future CA drought risk. However, the increase in precipitation and other hydrological variables in CMIP5 $\mathrm{HIGH}-\mathrm{r}$ models during the winter implies adaptation measures focused on smoothing seasonal differences for affected agricultural, terrestrial, and aquatic systems, as well as effectively capturing enhanced winter runoff.

Models possess uncertainties, including shortcomings in their land surface modeling ${ }^{47,58}$ and a lack of soil moisture simulation assessments, ${ }^{13}$ which could impact the conclusions based on soil moisture metrics. Additional model uncertainties include possible overestimation of tropical convection, ${ }^{59}$ which could impact the El Niño-like tropical/extratropical dynamical response that is important for producing the increase in CA precipitation, and muted drought risk in CMIP5 HIGH-r models. Furthermore, CMIP5 models may be deficient in their ability to simulate the tropical Pacific SST response to warming. ${ }^{60-62}$ Although the lack of significant warming in the central/eastern tropical Pacific over the last few decades may support such a deficiency, it is also possible these recent tropical Pacific SST anomalies are driven by coupled interactions in the tropical Pacific. ${ }^{63}$ Moreover, there are fundamental arguments that support the CMIP5 tropical Pacific SST projections. The tropical overturning circulation is expected to weaken due to thermodynamical constraints-tropical precipitation increases at a slower rate than water vapor, so the tropical overturning circulation, including the Walker circulation and the equatorial easterly trade winds, slow down. The Bjerknes feedback, a positive feedback between trade wind intensity and the zonal SST gradient, implies that the above changes would lead to a reduced zonal SST gradient (i.e., relative warming of the central/ 
eastern tropical Pacific). Nonetheless, if central/eastern tropical Pacific SSTs do not warm in response to increasing greenhouse gases as projected by the CMIP5 models, CA may experience larger increases in drought risk than reported here.

\section{METHODS}

Trend and correlation significance

Ensemble mean trend significance is based on a standard t-test, accounting for the influence of serial correlation by using the effective sample size, $n\left(1-r_{1}\right)\left(1+r_{1}\right)^{-1}$, where $n$ is the number of years and $r_{1}$ is the lag-1 autocorrelation coefficient. Significance of enhanced drought risk is based on $t$-test for the difference of means. Significance of correlations is also based on a $t$-test with $N-2$ degrees of freedom, with the $t$-statistic equal to $r /\left[\left(1-r^{2}\right) /(N-2)\right]^{0.5}$. $N$ is the sample size (e.g., number of years) and $r$ is the correlation. Detrended correlations are estimated by first detrending the corresponding time series, and then calculating the correlation.

\section{Drought definition}

A drought year is defined as one in which a metric (e.g., P-E, SMB) falls below a 0.5 standard deviation $(\sigma)$ departure from the 1950-1999 climatological mean; the change in drought risk is defined as the difference in the probability of drought from 2050-2099 relative to 1950-1999. "Extreme" drought requires a $-1 \sigma$ departure from the 1950-1999 mean. Multi-annual drought is defined similarly, but requires three consecutive $-0.5 \sigma$ departures $(-1 \sigma$ for multi-annual extreme drought) from the 1950-1999 climatological mean. Probabilities are calculated for each model, and then averaged to form the ensemble mean. Significance of the change in drought risk is based on a standard $t$ test.

\section{Data availability}

The data and code that support the findings of this study are available from the corresponding author upon reasonable request.

\section{ACKNOWLEDGEMENTS}

This study was funded by NSF award AGS-1455682.

\section{AUTHOR CONTRIBUTIONS}

R.J.A. conceived the project, designed the study, performed the analysis and wrote the paper. R.G.A. assisted with interpretation and writing. All figures and images were created by the authors.

\section{ADDITIONAL INFORMATION}

Supplementary information accompanies the paper on the npj Climate and Atmospheric Science website (https://doi.org/10.1038/s41612-018-0032-x).

Competing interests: The authors declare no competing interests.

Publisher's note Springer Nature remains neutral with regard to jurisdictional claims in published maps and institutional affiliations.

\section{REFERENCES}

1. Feng, S. \& Fu, Q. Expansion of global drylands under a warming climae. Atmos. Chem. Phys. 13, 10081-10094 (2013).

2. Dai, A. Increasing drought under global warming in observations and models. Nat. Clim. Change 3, 52-58 (2013)

3. Cook, B. I., Smerdon, J. E., Seager, R. \& Coats, S. Global warming and 21 st century drying. Clim. Dyn. 43, 2607-2627 (2014).

4. Seager, R. et al. Model projections of an imminent transition to a more arid climate in southwestern North America. Science 316, 1181-1184 (2007).

5. Seager, R. \& Vecchi, G. A. Greenhouse warming and the 21 st century hydroclimate of southwestern North America. Proc. Natl. Acad. Sci. 107, 21277-21282 (2010).

6. Cayan, D. R. et al. Future dryness in the southwest US and the hydrology of the early 21 st century drought. Proc. Natl. Acad. Sci. 107, 21271-21276 (2010).
7. Diffenbaugh, N. S., Swain, D. L. \& Touma, D. Anthropogenic warming has increased drought risk in California. Proc. Natl. Acad. Sci. 112, 3931-3936 (2015).

8. Williams, A. P. et al. Contribution of anthropogenic warming to California drought during 2012-2014. Geophys. Res. Lett. 42, 6819-6828 (2015)

9. Held, I. M. \& Soden, B. J. Robust responses of the hydrological cycle to global warming. J. Clim. 19, 5686-5699 (2006).

10. Meehl, G. A. et al. Global climate projections. in Climate Change 2007: The Physical Science Basis. Contribution of Working Group I to the Fourth Assessment Report of the Intergovernmental Panel on Climate Change (Eds Solomon, S., Qin, D. Manning, M., Chen, Z., Marquis, M., Averyt, K. B., Tignor, M. \& Miller, H. L.) (Cambridge University Press, Cambridge, United Kingdom and New York, NY USA, 2007).

11. Seidel, D. J., Fu, Q., Randel, W. J. \& Reichler, T. J. Widening of the tropical belt in a changing climate. Nat. Geosci. 1, 21-24 (2008).

12. Allen, R. J., Sherwood, S. C., Norris, J. R. \& Zender, C. S. Recent Northern Hemisphere tropical expansion primarily driven by black carbon and tropospheric ozone. Nature 485, 350-354 (2012).

13. Collins, M. et al. Long-term climate change: projections, commitments and irreversibility. in Climate Change 2013: The Physical Science Basis. Contribution of Working Group I to the Fifth Assessment Report of the Intergovernmental Panel on Climate Change (Eds Stocker, T. F., Qin, D., Plattner, G.-K., Tignor, M., Allen, S. K., Boschung, J., Nauels, A., Xia, Y., Bex, V. \& Midgley, P. M.) (Cambridge University Press, Cambridge, United Kingdom and New York, NY, 2013).

14. Seager, R. et al. Projections of declining surface-water availability for the southwestern United States. Nat. Clim. Change 3, 482-486 (2013).

15. Ault, T. R., Cole, J. E., Overpeck, J. T., Pederson, G. T. \& Meko, D. M. Assessing the risk of persistent drought using climate model simulations and paleoclimate data. J. Clim. 27, 7529-7549 (2014).

16. Cook, B. I., Ault, T. R. \& Smerdon, J. E. Unprecedented 21 st century drought risk in the American Southwest and Central Plains. Sci. Adv. https://doi.org/10.1126/ sciadv.1400082 (2015).

17. Seneviratne, S. I. et al. Changes in climate extremes and their impacts on the natural physical environment. in Managing the Risks of Extreme Events and Disasters to Advance Climate Change Adaptation (Eds Field, C. B., Barros, V., Stocker, T. F., Qin, D., Dokken, D. J., Ebi, K. L., Mastrandrea, M. D., Mach, K. J., Plattner, G.-K. Allen, S. K., Tignor, M., Midgley, P.M.) A Special Report of Working Groups I and II of the Intergovernmental Panel on Climate Change (IPCC). 109-230 (Cambridge University Press, Cambridge, UK, and New York, NY, USA, 2012).

18. Burke, E. J. \& Brown, S. J. Evaluating uncertainties in the projection of future drought. J. Hydrometeor. 9, 292-299 (2008).

19. Palmer, W. C. Meteorological drought. Res. Pap. 45, 1-58 (1965).

20. Sheffield, J., Wood, E. F. \& Roderick, M. L. Little change in global drought over the past 60 years. Nature 491, 435-438 (2012).

21. Hoerling, M. P. et al. Is a transition to semipermanent drought conditions imminent in the U.S. Great Plains? J. Clim. 25, 8380-8386 (2012).

22. Cheng, L. et al. How has human-induced climate change affected California drought risk? J. Clim. 29, 111-120 (2016).

23. Cayan, D. R., Mauer, E. P., Dettinger, M. D., Tyree, M. \& Hayhoe, K. Climate change scenarios for the California region. Clim. Change 87, S21-S42 (2008).

24. Pierce, D. W. et al. Probabilistic estimates of future changes in California temperature and precipitation using statistical and dynamical downscaling. Clim. Dyn.https://doi.org/10.1007/s00382-012-1337-9 (2012).

25. Neelin, J. D., Langenbrunner, B., Meyerson, J. E., Hall, A. \& Berg, N. California winter precipitation change under global warming in the Coupled Model Intercomparison Project Phase 5 ensemble. J. Clim. 26, 6238-6256 (2013).

26. Langenbrunner, B., Neelin, J. D., Lintner, B. R. \& Anderson, B. T. Regional patterns of precipitation change uncertainty among CMIP5 models with a focus on the midlatitude Pacific storm track. J. Clim. 28, 7857-7872 (2015).

27. Allen, R. J. \& Luptowitz, R. El Niño-like teleconnection increases California precipitation in response to warming. Nat. Commun. https://doi.org/10.1038/ ncomms16055 (2017).

28. Chang, E. K. M., Zheng, C., Lanigan, P., Yau, A. M. W. \& Neelin, J. D. Significant modulation of variability and projected change in California winter precipitation by extratropical cyclone activity. Geophys. Res. Lett. 42, 5983-5991 (2015).

29. Seager, R. et al. Dynamical and thermodynamical causes of large-scale changes in the hydrological cycle over North America in response to global warming. J. Clim. 27, 7921-7948 (2014).

30. Taylor, K. E., Stouffer, R. J. \& Meehl, G. A. An overview of CMIP5 and the experiment design. Bull. Am. Meteorol. Soc. 93, 485-498 (2012).

31. Hayhoe, K. et al. Emissions pathways, climate change, and impacts on California. Proc. Natl. Acad. Sci. 101, 12422-12427 (2008).

32. Giannini, A., Saravanan, R. \& Chang, P. Oceanic forcing of Sahel rainfall on interannual to interdecadal time scales. Science 302, 1027-1030 (2003).

33. Schubert, S. D., Suarez, M. J., Pegion, P. J., Koster, R. D. \& Bacmeister, J. T. On the cause of the 1930s Dust Bowl. Science 303, 1855-1859 (2004). 
34. McCabe, G. J., Palecki, M. A. \& Betancourt, J. L. Pacific and Atlantic Ocean influences on multidecadal drought frequency in the United States. Proc. Natl. Acad. Sci. 101, 4136-4141 (2004).

35. Seager, R., Kushnir, Y., Herweijer, C., Naik, N. \& Velez, J. Modeling of tropical forcing of persistent droughts and pluvials over western North America: 1856-2000. J. Clim. 18, 4065-4088 (2005).

36. Hoerling, M., Hurrell, J., Eischeid, J. \& Phillips, A. Detection and attribution of twentieth-century northern and southern African rainfall change. J. Clim. 19, 3989-4008 (2006)

37. Schubert, S. et al. A US CLIVAR project to assess and compare the responses of global climate models to drought-related SST forcing patterns: overview and results. J. Clim. 22, 5251-5272 (2009).

38. Hoerling, M., Eischeid, J. \& Perlwitz, J. Regional precipitation trends: distinguishing natural variability from anthropogenic forcing. J. Clim. 23, 2131-2145 (2010).

39. Kam, J., Sheffield, J. \& Wood, E. F. Changes in drought risk over the contiguous United States (1901-2012): the influence of the Pacific and Atlantic Oceans. Geophys. Res. Lett. 41, 5897-5903 (2014).

40. Coats, S., Smerdon, J. E., Cook, B. I. \& Seager, R. Stationarity of the tropical Pacific teleconnection to North America in CMIP5/PMIP3 model simulations. Geophys. Res. Lett. 40, 4927-4932 (2013)

41. Deser, C., Simpson, I. R., McKinnon, K. A. \& Phillips, A. S. The Northern Hemisphere extratropical atmospheric circulation response to ENSO: how well do we know it and how do we evaluate models accordingly? J. Clim. 30, 5059-5082 (2017).

42. Pavia, E. G. Changes in the ENSO-rainfall relationship in the Mediterranean California border region. Atmos. Sci. Lett. 18, 183-186 (2017).

43. Jong, B.-T., Ting, M. \& Seager, R. El Niño's impact on California precipitation: seasonality, regionality, and El Niño intensity. Environ. Res. Lett. 11, 054021 (2016).

44. Gao, Y. et al. Robust spring drying in the southwestern U.S. and seasonal migration of wet/dry patterns in a warmer climate. Geophys. Res. Lett. 41, 1745-1751 (2014).

45. Dorigo, W. et al. ESA CCI Soil Moisture for improved Earth system understanding: state-of-the art and future directions. Remote Sens. Environ. 203, 185-215 (2017).

46. Rayner, N. A. et al. Global analyses of sea surface temperature, sea ice, and night marine air temperature since the late nineteenth century. J. Geophys. Res. 108, 4407 (2003).

47. Yuan, S. \& Quiring, S. M. Evaluation of soil moisture in CMIP5 simulations over the contiguous United States using in situ and satellite observations. Hydrol. Earth Syst. Sci. 21, 2203-2218 (2017)

48. Svoboda, M., Hayes, M. \& Wood, D. Standardized Precipitation Index User Guide. WMO-No. 1090 (Geneva, World Metoerological Organization, 2012).

49. Vicente-Serrano, S. M., Beguera, S., López-Moreno, J. I., Angulo, M. \& El Kenawy, A. A new global $0.5^{\circ}$ gridded dataset (1901-2006) of a multiscalar drought index: Comparison with current drought index datasets based on the Palmer Drought Severity Index. J. Hydrometeor. 11, 1033-1043 (2010).

50. Dai, A., Trenberth, K. E. \& Qian, T. A global dataset of Palmer Drought Severity Index for 1870-2002: Relationship with soil moisture and effects of surface warming. J. Hydrometeor. 5, 1117-1130 (2004).

51. Xia, Y. et al. Continental-scale water and energy flux analysis and validation for the North American Land Data Assimilation System project phase 2 (NLDAS-2): 1.
Intercomparison and application of model products. J. Geophys. Res. 117, D03109 (2012).

52. Xia, Y. et al. Continental-scale water and energy flux analysis and validation for North American Land Data Assimilation System project phase 2 (NLDAS-2): 2. Validation of model-simulated streamflow. J. Geophys. Res. 117, D03110 (2012).

53. Maurer, E. P. Uncertainty in hydrologic impacts of climate change in the Sierra Nevada, California, under two emissions scenarios. Clim. Change 82, 309-325 (2007).

54. Berg, N. \& Hall, A. Anthropogenic warming impacts on California snowpack during drought. Geophys. Res. Lett. 44, 2511-2518 (2017).

55. Gergel, D. R., Nijssen, B., Abatzoglou, J. T., Lettenmaier, D. P. \& Stumbaugh, M. R. Effects of climate change on snowpack and fire potential in the western USA. Clim. Change 141, 287-299 (2017).

56. Nalbantis, I. \& Tsakiris, G. Assessment of hydrological drought revisited. Water Resoures Res. 23, 881-897 (2009).

57. Sridhar, V., Hubbard, K. G., You, J. \& Hunt, E. D. Development of the soil moisture index to quantify agricultural drought and its "user friendliness" in severity-areaduration assessment. J. Hydrometeorol. 9, 660-676 (2008).

58. Henderson-Sellers, A., Irannejad, P. \& McGuffie, K. Future desertification and climate change: the need for land-surface system evaluation improvement. Glob. Planet. Change 64, 129-138 (2008).

59. Sohn, B.-J., Lee, S., Chung, E.-S. \& Song, H.-J. The role of the dry static stability for the recent change in the Pacific Walker circulation. J. Clim. 29, 2765-2779 (2016).

60. Kohyama, T., Hartmann, D. L. \& Battisti, D. S. La Niña-like mean-state response to global warming and potential oceanic roles. J. Clim. 30, 4207-4225 (2017).

61. Kohyama, T. \& Hartmann, D. L. Nonlinear ENSO warming suppression (NEWS). J. Clim. 30, 4227-4251 (2017).

62. Coats, S. \& Karnauskas, K. B. Are simulated and observed twentieth century tropical Pacific sea surface temperature trends significant relative to internal variability? Geophys. Res. Lett. 44, 9928-9937 (2017).

63. Delworth, T. L., Zeng, F., Rosati, A., Vecchi, G. A. \& Wittenberg, A. T. A link between the hiatus in global warming and North American drought. J. Clim. 28, 3834-3845 (2015).

Open Access This article is licensed under a Creative Commons Attribution 4.0 International License, which permits use, sharing, adaptation, distribution and reproduction in any medium or format, as long as you give appropriate credit to the original author(s) and the source, provide a link to the Creative Commons license, and indicate if changes were made. The images or other third party material in this article are included in the article's Creative Commons license, unless indicated otherwise in a credit line to the material. If material is not included in the article's Creative Commons license and your intended use is not permitted by statutory regulation or exceeds the permitted use, you will need to obtain permission directly from the copyright holder. To view a copy of this license, visit http://creativecommons. org/licenses/by/4.0/.

(c) The Author(s) 2018 